\title{
叔膦促进下两种亲电试剂之间的环化反应研究进展
}

\author{
周荣*, 刘蓉芳 $^{a}$ 李瑞丰 ${ }^{a}$ 贺峥杰 $*, b$ \\ $\left({ }^{a}\right.$ 太原理工大学化学化工学院 太原 030024) \\ ( ${ }^{b}$ 南开大学元素有机化学国家重点实验室 天津化学化工协同创新中心 天津 300071)
}

\begin{abstract}
摘要 发展环状化合物的高效合成方法对药物分子、天然产物及其他功能有机分子的合成具有重要意义. 近年来, 叔 膦促进下两种亲电试剂之间的环化反应，由于具有原料简单易得、反应条件温和、且无需金属参与等优点，同时为多 种碳环及杂环化合物的合成提供了高效的新途径, 因而受到了合成化学家的广泛关注. 这类反应通常经过叔膦对亲电 试剂进行亲核加成, 产生两性离子活性中间体这一关键步骤来完成. 根据两性离子的不同来源, 综述了叔膦促进下缺 电子联烯、Morita-Baylis-Hillman 烯丙基化合物、缺电子烯烃与其他亲电试剂之间的环化反应.
\end{abstract}

关键词 叔膦; 亲电试剂; 两性离子; 环化反应

\section{Progress in Phosphine-Promoted Annulations between Two Electrophiles}

\author{
Zhou, Rong $^{*, a} \quad$ Liu, Rongfang ${ }^{a} \quad$ Li, Ruifeng $^{a} \quad$ He, Zhengjie*,b \\ ( ${ }^{a}$ College of Chemistry and Chemical Engineering, Taiyuan University of Technology, Taiyuan 030024) \\ ( ${ }^{b}$ State Key Laboratory of Elemento-Organic Chemistry, Collaborative Innovation Center of \\ Chemical Science and Engineering (Tianjin), Nankai University, Tianjin 300071)
}

\begin{abstract}
The development of highly efficient synthetic methods of cyclic compounds is of great significance in the syntheses of pharmaceutically active molecules, natural products and other functional organic molecules. Recently, phosphine-promoted annulations of two electrophiles, which provide highly efficient access to various carbo- and heterocycles, have attracted extensive interest from synthetic chemists due to their merits such as ready availability of starting materials, mild and metal-free conditions. Generally, this kind of annulation reaction proceeds through a key step to generate an active zwitterionic intermediate via nucleophilic addition of the phosphine to an electrophile. According to different sources of the zwitterions, this review summarizes the recent progress in phosphine-promoted annulations of electron-deficient allenes, Morita-Baylis-Hillman allylic adducts, and electron-deficient alkenes with other electrophiles.
\end{abstract}

Keywords phosphine; electrophile; zwitterions; annulations

叔膦作为一类重要的有机磷化合物, 在有机合成中 具有重要的用途 ${ }^{[1}$. 叔膦具有较强的夺氧能力(还原性), 在经典有机人名反应如 Wittig 反应、Mitsunobu 反应、 及 Staudinger 反应中, 磷的夺氧能力对完成相关的化学 转化起到了关键作用 ${ }^{[2]}$. 叔膦还具有较强的亲核性(源 于磷原子给出孤对电子的能力和可极化性). 近年来, 叔膦作为亲核有机催化剂作用下的有机新反应大量涌 现, 为其在有机合成中的应用开辟了新的领域 ${ }^{[3]}$. 由于 叔膦这些特殊的化学性质决定了它在有机合成中具有
广泛的用途，研究叔膦促进的有机合成方法学已成为当 今有机合成化学领域中的一个重要研究方向, 吸引了有 机化学家浓厚的兴趣.

近十几年来，随着叔膦催化 $\mathrm{Lu}[3+2]$ 环化反应的 发现 ${ }^{[4]}$, 涌现了许多亲核性膦促进的环化反应，为官能 团化的环状化合物、特别是五元、六元及七元环状化合 物的高效合成, 提供了新方法 ${ }^{[3 \mathrm{~d} \sim 3 \mathrm{~h}]}$. 在已报道的叔膦促 进的环化反应中, 通常涉及两种不同亲电试剂的串联环 化，并且反应一般经过叔膦对其中一种亲电性底物中极

\footnotetext{
*E-mail: zhourong@tyut.edu.cn; zhengjiehe@nankai.edu.cn

Received June 29, 2014; revised August 12, 2014; published online August 28, 2014.

Project supported by the National Natural Science Foundation of China (No. 21272119), the Qualified Personnel Foundation of Taiyuan University of Technology (No. tyutrc-201357a), and the Youth Foundation of Taiyuan University of Technology (No. 2013Z043).

国家自然科学基金(No. 21272119)、太原理工大学引进人才基金(No. tyutrc-201357a)及太原理工大学青年基金(No. 2013Z043)资助项目.
} 
化的碳碳多重键进行亲核加成, 产生两性离子活性中间 体这一关键步骤来完成. 因此, 对带有极化多重键的亲 电性底物的合理选择, 便成为发展叔膦促进下两种不同 亲电试剂之间新的环化反应的关键. 目前被广泛研究的 亲电性底物主要包括缺电子联烯、Morita-Baylis-Hillman (MBH)烯丙基化合物及缺电子烯烃(Scheme 1).

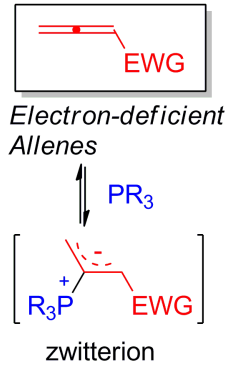

A

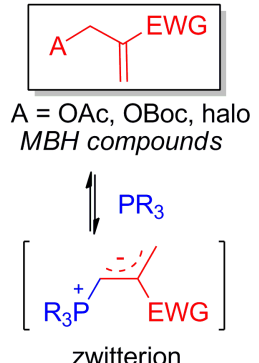

B

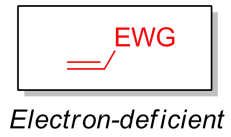

Alkenes

॥ $\mathrm{PR}_{3}$



C
Scheme 1

在叔膦的亲核进攻下, 缺电子联烯、MBH 烯丙基化 合物及缺电子烯烃能分别转变成相应的两性离子 $\mathbf{A} 、 \mathbf{B}$ 及 $\mathbf{C}$, 所得两性离子再与其他亲电试剂串联环化, 从而 完成不同类型环化反应, 构建不同结构环状化合物 (Scheme 1). 本文将扼要阐述叔膦促进下缺电子联烯、 $\mathrm{MBH}$ 烯丙基化合物及缺电子烯烃与各种亲电试剂的环 化反应类型.

\section{1 叔膦促进下缺电子联烯与亲电试剂的环化反 应类型}

缺电子联烯是指在联烯结构上连有拉电子基团的
一类化合物, 受拉电子基团的影响, 缺电子联烯的 $\alpha, \beta$ 碳碳双键容易受到亲核性叔膦的进攻. 当叔膦进攻缺电 子联烯的 $\beta$ 位后, 形成一类重要的 1,3-偶极中间体，该 中间体可以与一系列亲电试剂，包括活化烯烃、醛、酮 及亚胺等发生多种形式的环化反应(Eq. 1). 近年来这一 领域发展迅速，涌现了包括 $[3+2]$ 及 $[4+2]$ 环化反应在 内的众多具有重要合成意义的新反应.

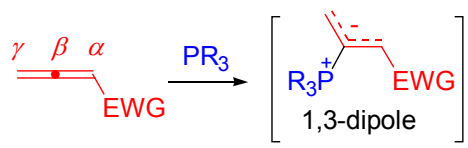

\section{1 叔膦促进下缺电子联烯与亲电试剂的 $[3+2]$ 环化 反应}

1995 年, 陆熙炎等 ${ }^{[4]}$ 首次报道了叔膦催化下缺电子 联烯与活化烯烃的 $[3+2]$ 环化反应. 在 $10 \mathrm{~mol} \%$ 三苯基 膦的催化下, 联烯酸酯(1)与丙烯酸乙酯 $(2)$ 能发生 $[3+2]$ 环化反应，以较高的收率生成环戊烯衍生物 3 , 其中以 联烯 $\alpha$-位碳负离子对丙烯酸酯加成而生成的产物 $\mathbf{3 \alpha}$ 为 主(Scheme 2). 研究发现丙烯酸酯、马来酸酯、富马酸 酯、丙烯腈及甲基乙烯酩等活化烯烃都表现出了较好的 反应性, 能以较高的收率及立体选择性得到环化产物. 值得一提的是, 对于马来酸酯, 反应能得到单一的顺式 立体异构体, 而对于富马酸酯, 却能得到单一的反式立 体异构体.

作者提出了下图所示机理(Scheme 2), 叔膦对联烯 亲核进攻生成 1,3-偶极中间体 4, 该中间体以其 $\alpha$-或 $\gamma$ 位碳负对活化烯烃亲核进攻( $\alpha$-位进攻方式占主导)及随

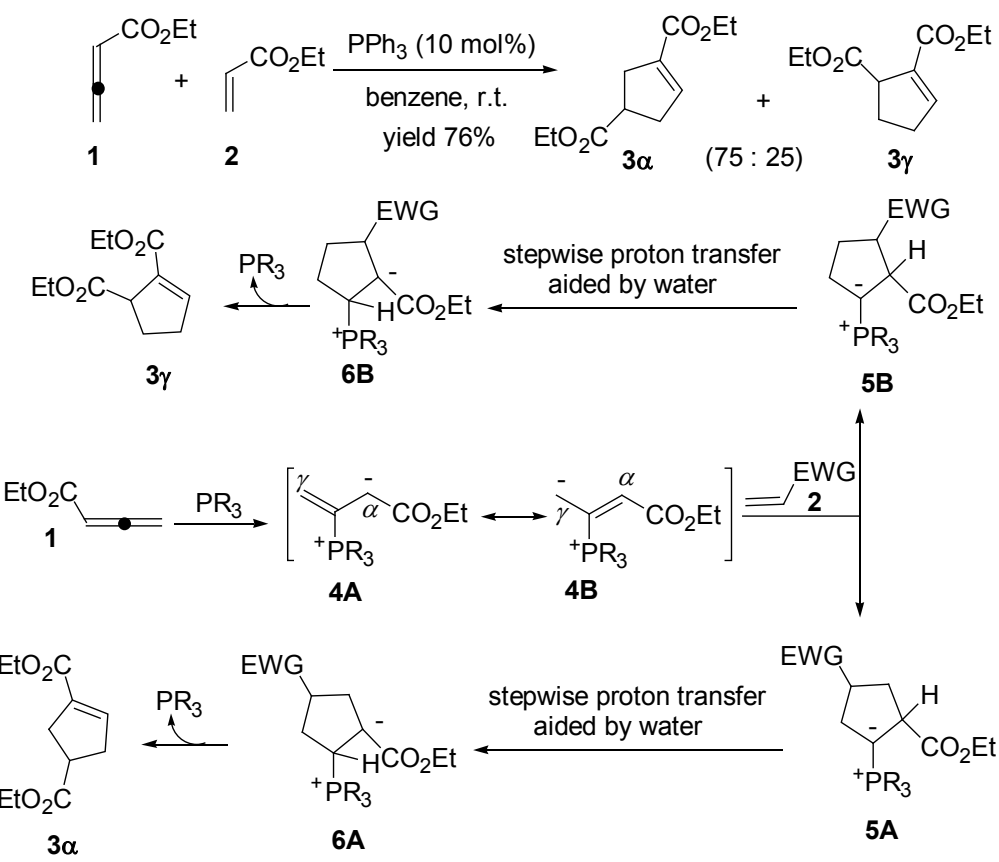

Scheme 2 
后分子内 Michael 加成, 得到叶立德 $\mathbf{5}$, 最后经质子转移 及叔膦的消除, 生成 $[3+2]$ 环化产物 3. 最近, 余志祥 ${ }^{[5]}$ 与 Kwon 等 ${ }^{[6]}$ 通过一系列的研究证实了该机理的正确性, 并且前者还通过理论化学计算和 $\mathrm{H} / \mathrm{D}$ 交换实验, 证明了 在上述机理中, 质子转移步骤是一个微量水参与的分步 过程.

随后，陆熙炎等 ${ }^{[7]}$ 发现，磺酰亚胺同样能与联烯酸 酯发生 $[3+2]$ 环化反应, 以较高的收率及单一的区域选 择性生成二氢吡咯衍生物. 反应在机制上类似于上述与 活化烯烃的反应过程. 值得一提的是, 在该反应中, 叔 膦与联烯酸酯所生成的 1,3-偶极子仅高度区域选择性地 以 $\alpha$-位碳负对亚胺亲核加成, 得到单一的立体异构体产 物(Scheme 3). 最近, Kwon 等 ${ }^{[8]}$ 拓展了该反应的联烯酸 酯底物范围, 发现在三丁基膦的催化下, $\gamma$-位取代联烯 酸酯同样表现出优秀的反应活性. 同时本课题组 ${ }^{[9]}$ 研究 发现, 在一种新颖的对空气稳定的环状叔膦 1,3,5-三氮 杂-7-磷杂金刚烷(PTA)的催化下, $\gamma$-位取代联烯酸酯还 可以与硫代磷酰亚胺发生 $[3+2]$ 环化反应, 并且所生成 的产物可以在甲醇中顺利脱去磷酰基, 得到相应的二氢 吡咯衍生物(Scheme 4).

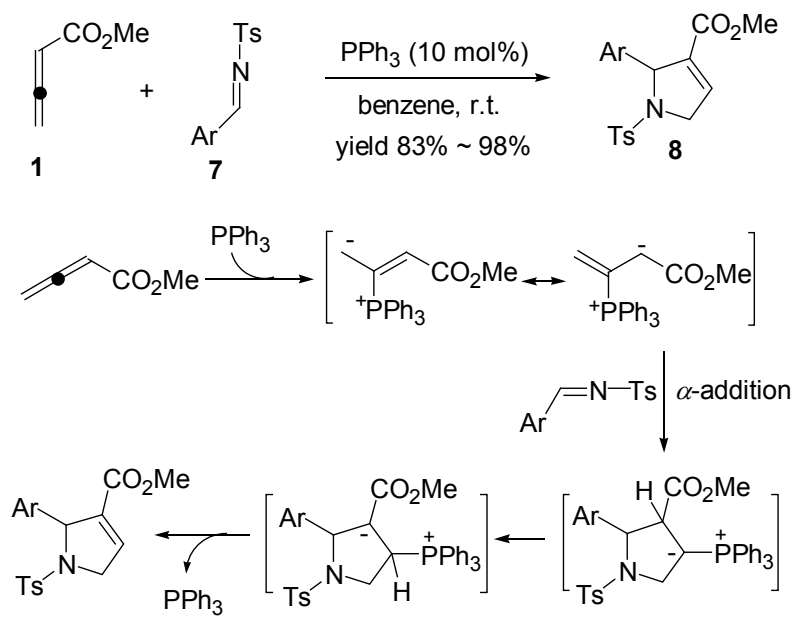

Scheme 3

叔膦催化下, 缺电子联烯与活化烯烃及亚胺的 $[3+$ 2]环化反应具有原料简单易得、反应条件温和、原子经 济性高、立体选择性好等优点, 为构建药物分子 ${ }^{[10]}$ 及天 然产物 ${ }^{[11]}$ 中广泛存在的五元碳环及杂环骨架提供了高 效的途径. 该反应被陆熙炎教授首次报道以来, 就引起 了人们广泛的研究兴趣, 并得以迅速发展, 其中有关该 反应的不对称转化也在近年来取得了较好的研究成果, 涌现了许多具有优秀对映体选择性的报道 ${ }^{[\mathrm{ld} \sim 3 \mathrm{~h}]}$.

醛作为一类重要的亲电试剂, 具有与活化烯烃及亚 胺相似的反应活性, 但有关叔膦催化下缺电子联烯与酫 的 $[3+2]$ 环化反应直到最近才由本课题组报道 ${ }^{[12]}$. 研究

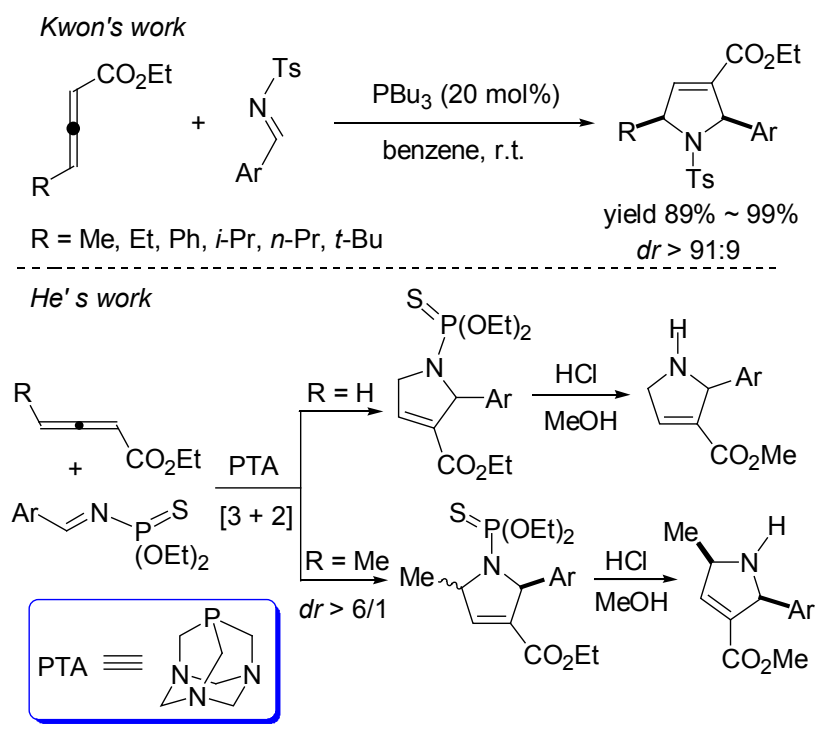

\section{Scheme 4}

发现, 在对氟三苯基膦催化下, $\gamma$-甲基联烯酸酯与芳香 醛能发生 $[3+2]$ 环化反应，以较高的收率及立体选择性 生成四氢呋喃衍生物(Eq. 2). 在该反应中 $\gamma$-位取代基的 结构对反应具有较大影响，将 $\gamma$-位甲基换成乙基或芐基， 前者只能获得较低收率, 后者则完全得不到 $[3+2]$ 环化 产物, 主要与醛发生烯化反应. 针对反应结果及机理探 究实验, 我们认为可能机理如 Scheme 5 所示. 叔膦对联 烯酸酯亲核进攻形成 1,3-偶极中间体 11, 随后经过一个 水参与的可逆氢转移过程, 生成烯丙基磷叶立德中间体 12 , 该中间体以烯丙基碳负离子 $12 \mathrm{~A}$ 对醛亲核加成得到 中间体 13, 接着经分子内双键迁移得到中间体 14, 最后
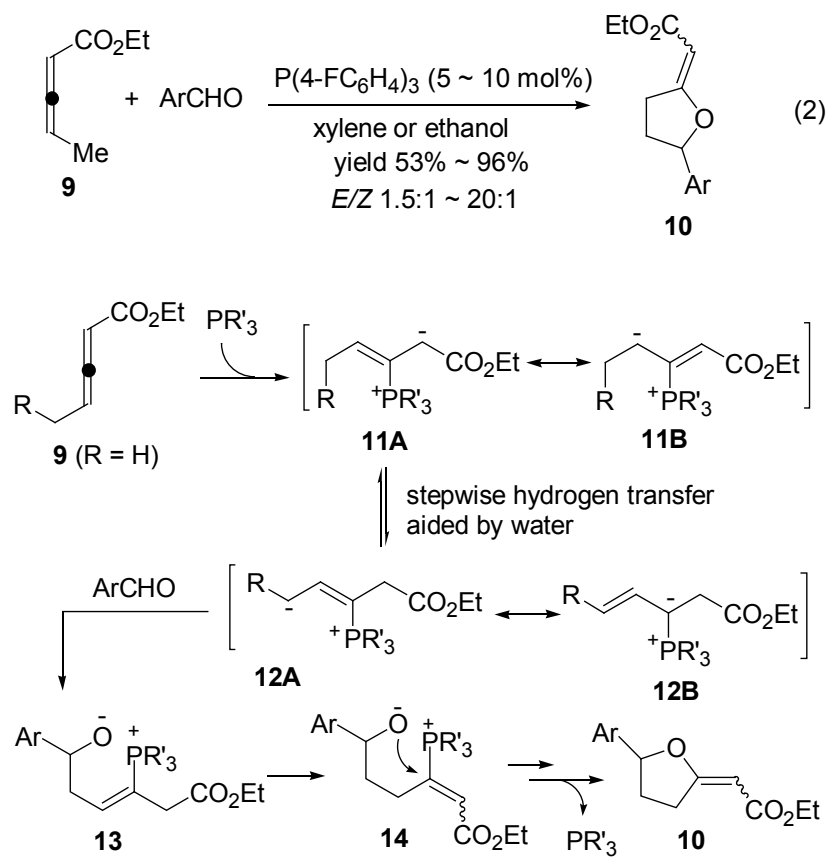

Scheme 5 
发生分子内 Michael 加成及叔膦催化剂的消去, 生成 $[3+2]$ 环化产物 10. 同前述联烯酸酯与活化烯烃或亚 胺的 [3+2]环化反应不同的是, 该反应所形成的 1,3偶极中间体 11 没有直接对醛羰基进行亲核加成，而 是经过氢迁移之后, 以烯丙基碳负离子 $12 \mathrm{~A}$ 的形式与 醛反应，得到联烯 $\gamma$-甲基参与成键的 $[3+2]$ 环化反应 产物.

2011 年，叶松等 ${ }^{[13]}$ 实现了联烯酸酯与三氟甲基酮 的 $[3+2]$ 环化反应, 以较高收率合成了二氢呋喃衍生物 (Scheme 6). 机理上, 同前述联烯酸酯与活化烯烃及亚 胺的 $[3+2]$ 环化反应过程类似, 并且在此反应中, 叔膦 与联烯酸酯形成的偶极子高度区域选择性地以 $\gamma$-碳负对 酮羰基亲核进攻，从而只生成了一种区域立体异构体产 物. 值得一提的是, 该反应得到的二氢呋喃衍生物经 $\mathrm{Pd} / \mathrm{C}$ 催化氢化, 能以高度的立体选择性得到反式四氢呋 喃衍生物.

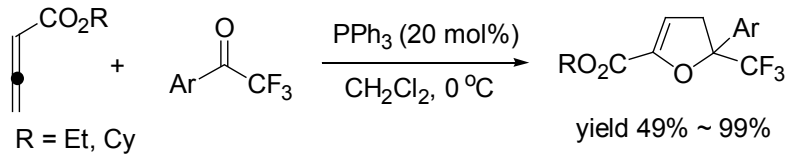

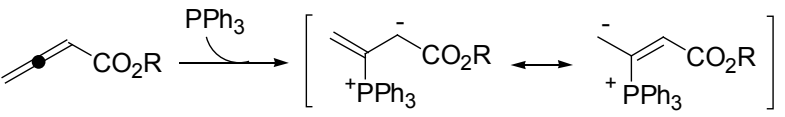

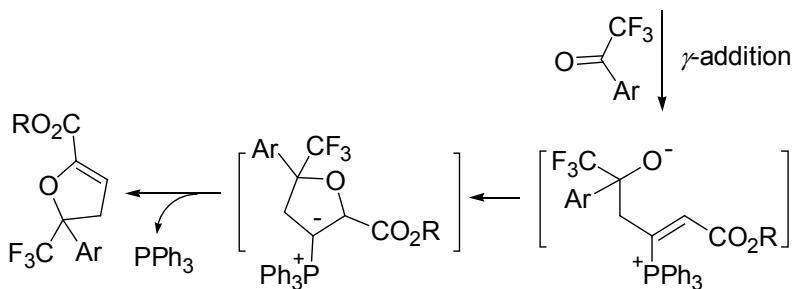

Scheme 6
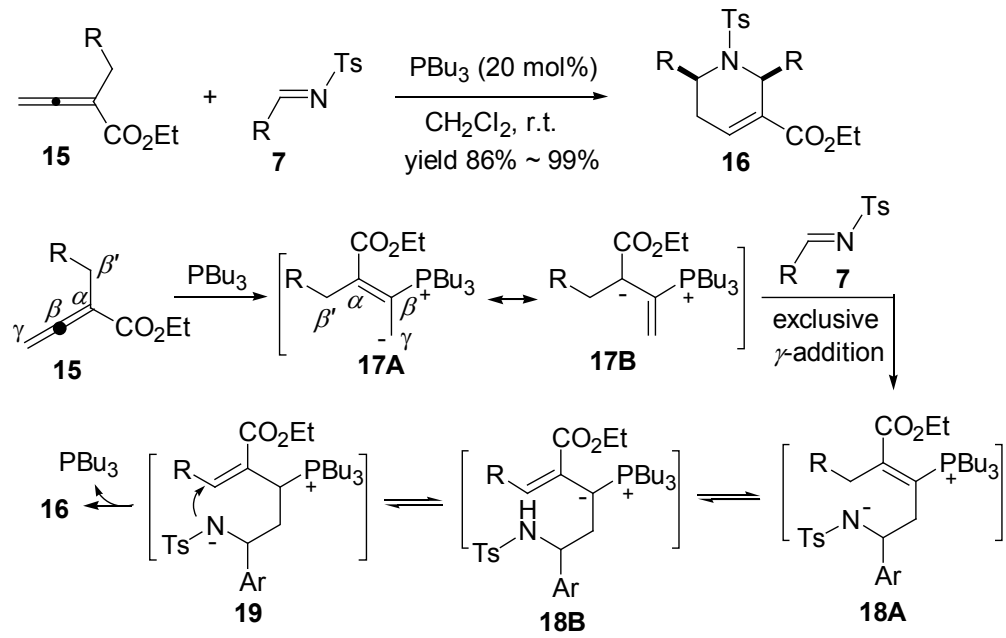

Scheme 7

\section{2 叔膦促进下缺电子联烯与亲电试剂的 $[4+2]$ 环化 反应}

2003 年, Kwon 小组 ${ }^{[14]}$ 首次报道了叔膦催化下, $\alpha$-位 取代联烯酸酯与磺酰亚胺的 [4+2]环化反应. 研究发现, 在三丁基膦的催化下， $\alpha$-位取代联烯酸酯与磺酰亚胺能 发生[4+2]环化反应，生成多取代的四氢吡啶衍生物。 不同芳基及杂环芳基取代的磺酰亚胺都表现出较好的 反应性，但水杨磺酰亚胺则不能发生反应. 值得一提是， 大体积的脂肪族亚胺如叔丁基磺酰亚胺，同样能顺利地 发生该反应，以较高的收率得到反应产物，而在前述的 $[3+2]$ 环化反应中，脂肪族的磺酰亚胺是不能够发生反 应的. 基于反应结果及相关机理探究实验，作者提出了 如下反应机制(Scheme 7). 首先叔膦对联烯酸酯亲核进 攻得到 1,3-偶极中间体 17, 由于 $\alpha$-位取代基位阻的影响, 该中间体区域选择性地以 $\gamma$-碳负 17A 对亚胺亲核加成, 得到中间体 $18 \mathrm{~A}$, 随后经氢迁移生成烯丙基磷叶立德 $18 B$ ，接着再经过氢迁移得到中间体 19 , 最后发生 6-endo 关环及叔膦的消除，得到环化产物 16. 作者认为 第一步的氢迁移，也就是由中间体 18A 生成 18B 的过程 是反应的决速步骤，因此增强 $\beta^{\prime}-\mathrm{H}$ 的酸性能够加快反应 速率，这在研究中得以证实，当 $\beta^{\prime}$-位连有拉电子取代的 芳基(如 4-氧基苯基)时，反应能在更短的时间内完成， 并得到更高的收率及立体选择性.

随后, Kwon 小组 ${ }^{[15]}$ 成功地将活化烯烃应用到该反 应中，实现了叔膦催化下， $\alpha$-甲基联烯酸酯与双氧基活 化烯烃的 [4+2]环化反应，高效合成了多取代环已烯衍 生物. 有趣的是，该反应对不同的叔膦催化剂得到了截 然不同的区域选择性结果。在六甲基亚磷酰三胺 (HMPT)的催化下，反应得到区域选择性的产物 21; 而 在 $\mathrm{P}\left(4-\mathrm{ClC}_{6} \mathrm{H}_{4}\right)_{3}$ 的催化下，则生成了另一种区域选择性 的产物 22 (Scheme 8). 根据上述缺电子联烯与亚胺的 




Scheme 8

$[4+2]$ 环化反应机理, 结合该反应的实验结果, 作者提 出如下反应机制: 叔膦对联烯酸酯亲核加成得到 1,3-偶 极中间体 23, 该中间体通过可逆的氢迁移过程生成中间 体 24. 当催化剂为 HMPT 时, 23 以 $\gamma$-位碳负对活化烯烃 亲核加成得到中间体 $\mathbf{2 5}$, 随后经过氢迁移生成中间体 26, 接着发生分子内 Michael 加成及叔膦的消除得到环 化产物 21; 当催化剂为 $\mathrm{P}\left(4-\mathrm{ClC}_{6} \mathrm{H}_{4}\right)_{3}$ 时, 则以中间体 24 $\beta^{\prime}$-位碳负对活化烯烃亲核加成, 得到中间体 $\mathbf{2 7}$, 随后经 过氢迁移得到 28, 接着发生分子内 Michael 加成得到叶 立德中间体 29, 最后经过氢迁移及叔膦的消除得到反应 产物 22. 作者认为, 当采用相对缺电子的芳基膦催化剂 时, 中间体 24 所形成的叶立德中间体具有更好的稳定 性, 因此有利于 23 向 24 转化, 从而让随后的反应区域 选择性地在 $\beta^{\prime}$-位碳负上发生. 但作者进一步的研究发 现, 对于 $\beta^{\prime}$-位连有取代基(如芳基、烷基等)的联烯酸酯, 由于空间位阻的影响不利于 $\beta^{\prime}$-位碳负对活化烯烃亲核 进攻, 因此不管是在 HMPT 还是在缺电子性芳基膦的催
化下，都只区域选择性地生成了产物 21.

上述 $[4+2]$ 环化反应在有机合成中具有广泛的用 途, Kwon 等 ${ }^{[16]}$ 成功地将其应用到一系列天然产物的全 合成研究当中. 鉴于该反应的重要性, 有关其不对称转 化也在近年来得到迅速发展, 涌现了一系列具有优秀对 映体选择性的报道 ${ }^{[17]}$

最近，叶松等 ${ }^{[18]}$ 报道了联烯酸酯与酮的 $[4+2]$ 环化 反应. 研究发现, 在三苯基膦的催化下, $\alpha$-位取代联烯酸 酯与三氟甲基酮能发生 $[4+2]$ 环化反应，以较高的收率 及优秀的立体选择性生成含氟二氢吡喃衍生物(Scheme 9). 在该反应中，三氟甲基的存在起到至关重要的作用， 如将其换成氧基或酯基, 则不能发生反应. 该研究首次 实现了亚胺及活化烯烃外, 酮类化合物与联烯酸酯的 $[4+2]$ 环化反应. 机理上，同上述联烯酸酯与亚胺及活 化烯烃的 [4+2]环化反应过程类似，受空间位阻的影响， 形成的 1,3-偶极中间体仅以 $\gamma$-位碳负对酮羰基亲核进攻, 得到高度区域选择性的环化产物(Scheme 9).
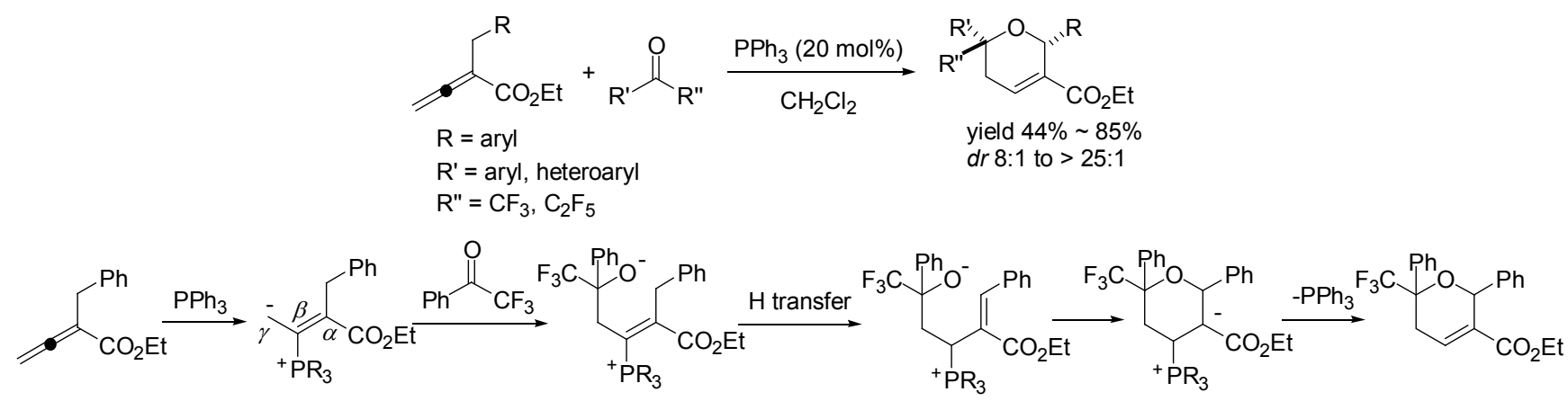

Scheme 9 
在上述 $[4+2]$ 环化反应中, 所采用的反应底物一般 为 $\alpha$-位取代联烯酸酯, 并且 $\alpha$-位取代基的存在对反应顺 利进行起到至关重要的作用. 最近, 黄有 ${ }^{[19]}$ 及 Marinetti 小组 ${ }^{[20]}$ 分别报道了 $\gamma$-位取代联烯酸酯的 $[4+2]$ 环化反应. 在 $\mathrm{PPh}_{3}$ 的催化下, $\gamma$-芐基联烯酸酯与 1,3-狮二酮或靛红 衍生的活化烯烃能发生 $[4+2]$ 环化反应, 以较高的收率 及立体选择性生成螺环已烯衍生物(Scheme 10). 反应机 理与前述 $[4+2]$ 环化反应略有不同, 在此反应中, 叔膦 对联烯酸酯亲核进攻形成的偶极体经过氢迁移后形成 $\delta$-位碳负离子, 随后对活化烯烃进行亲核加成, 再发生 后续反应，得到环化产物(Scheme 11).

众所周知, Diels-Alder 反应是构筑六元碳环或杂环 的经典方法, 但其反应活性及区域选择性由双烯体和亲 双烯体的分子轨道性质决定, 对某些结构特殊的六元环 状化合物的制备很难通过 Diels-Alder 反应来实现. 然 而, 叔膦促进下缺电子联烯与亲电试剂的 $[4+2]$ 环化反 应, 提供了一种在温和条件下, 原子经济性及立体选择 性地构建六元碳环及杂环的有效方法, 可以作为 Diels-Alder 反应的一个补充, 很好地弥补其在构建某些 结构特殊的六元环状化合物中的不足.

\section{3 叔膦促进下缺电子联烯与亲电试剂的其他环化反} 应

在叔膦的促进下，缺电子联烯除了能与活化烯烃、 亚胺及醛酮等发生经典的 $[3+2]$ 及 $[4+2]$ 环化反应外, 还可以与其他亲电试剂发生多种类型的环化反应 ${ }^{[21]}$.
与磺酰呋啶的 $[3+3]$ 环化反应，以较高的立体选择性及 较好的收率合成了四氢吡啶衍生物. 研究发现, 芳基取 代的呋啶表现出较好的反应性, 能得到较高的收率与立 体选择性; 烷基取代的叮啶在反应中立体选择性较差, 而无取代的呋啶则完全不能发生反应. 有趣的是, 在反 应过程中吹啶上的磺酰基团发生了相应的转化, 并经过 芳基重排与 $\mathrm{SO}_{2}$ 的释放, 得到氮上无取代的四氢吡定产 物. 反应机理如 Scheme 12 所示, 叔膦对联烯酸酯亲核 进攻生成 1,3-偶极中间体 32, 随后经氢迁移得到 vinylogous 叶立德中间体 33. 该中间体对呋啶 30 亲核进 攻及呋啶开环，得到中间体 34，随后经氢迁移得到中间 体 35, 接着发生分子内芳基取代并释放 $\mathrm{SO}_{2}$, 得到中间 体 36, 最后发生分子内 Michael 加成及叔膦的消除, 得 到反应产物 31.

最近，郭红超与 Kwon 等 ${ }^{[23]}$ 报道了叔膦催化下，联 烯酸酯与偶氮亚胺类化合物的 $[3+2] 、[3+3] 、[4+3]$ 及 $[3+2+3]$ 环化反应，成功地合成了几类氮杂双环化合 物. 值得一提的是，根据叔膦亲核性及联烯酸酯结构的 不同，可以化学选择性地实现单一类型的环化反应. 当 联烯酸酯上取代基 $\mathrm{R}^{2}$ 为 $\mathrm{H}, \mathrm{R}^{3}$ 为连有芳基或烷基的亚甲 基时, 在亲核性较强的 $\mathrm{PBu}_{3}$ 或 $\mathrm{PMe}_{3}$ 催化下, 主要发生 $[3+2]$ 环化反应; 当 $R^{2}$ 为 $H$ 或烷基, $R^{3}$ 为 $H$ 或连有拉电 子基团的亚甲基时, 在 $\mathrm{PBu}_{3}$ 的催化下, 主要发生 [3+3] 或 $\left[4+3\right.$ ]环化反应; 当 $R^{2}, R^{3}$ 都为 $H$ 时，在亲核性较弱的 $\mathrm{PCy}_{3}$ 催化下, 主要发生 $[3+2+3]$ 环化反应(Scheme 13).

2009 年, Kwon 等 ${ }^{[22]}$ 报道了叔膦促进下, 联烯酸酯
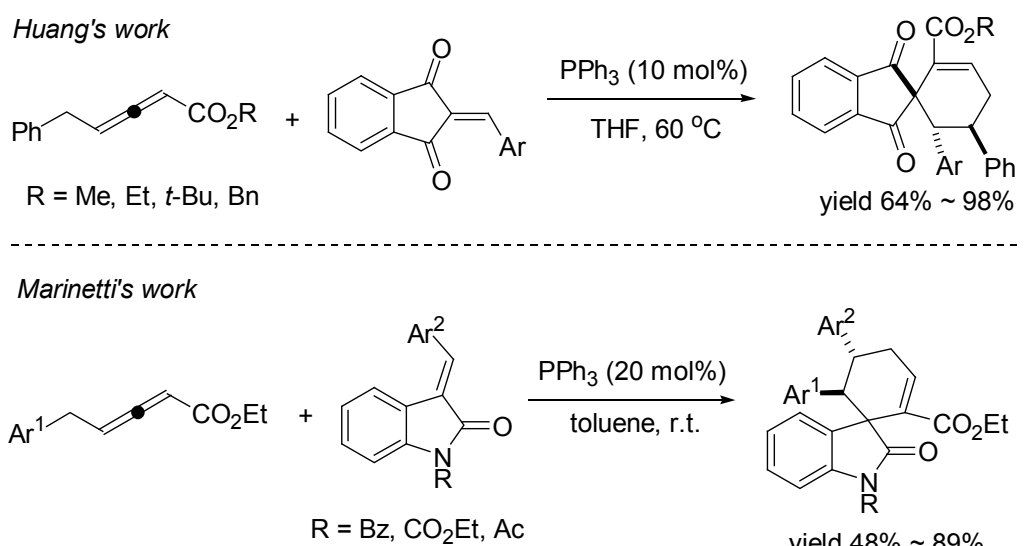

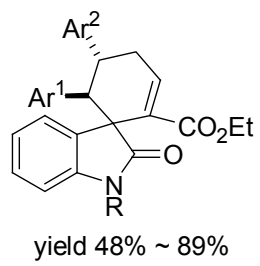

Scheme 10

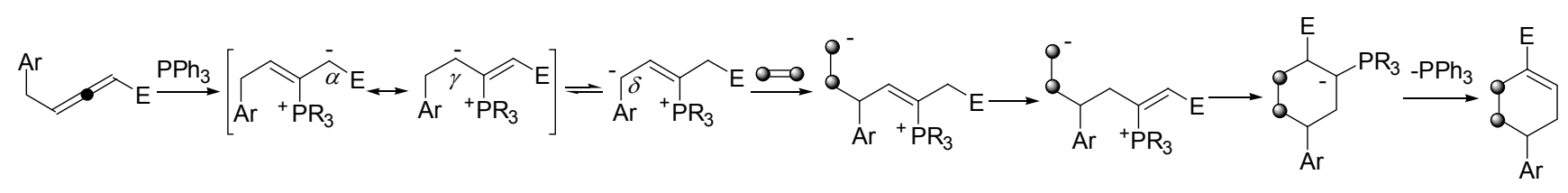

Scheme 11 
<smiles>[R]C1C([R])N1[N+](=O)c1ccc([N+](=O)[O-])cc1</smiles>

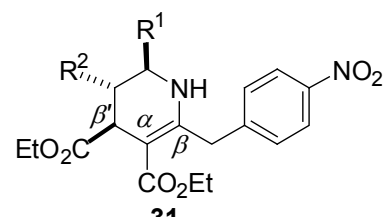

31

$37 \% \sim 98 \%$ yields

up to $97: 3 d r$

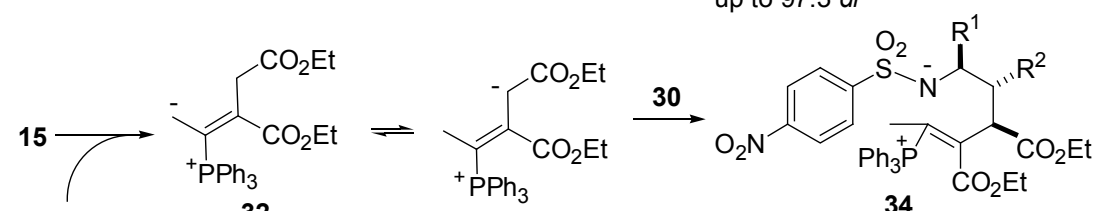

$32 \quad 33$



$\downarrow \mathrm{H}$ shift

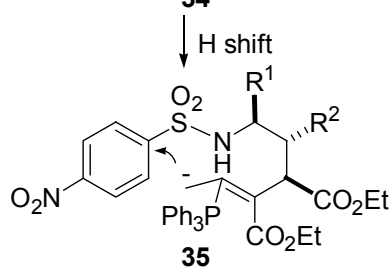

Scheme 12

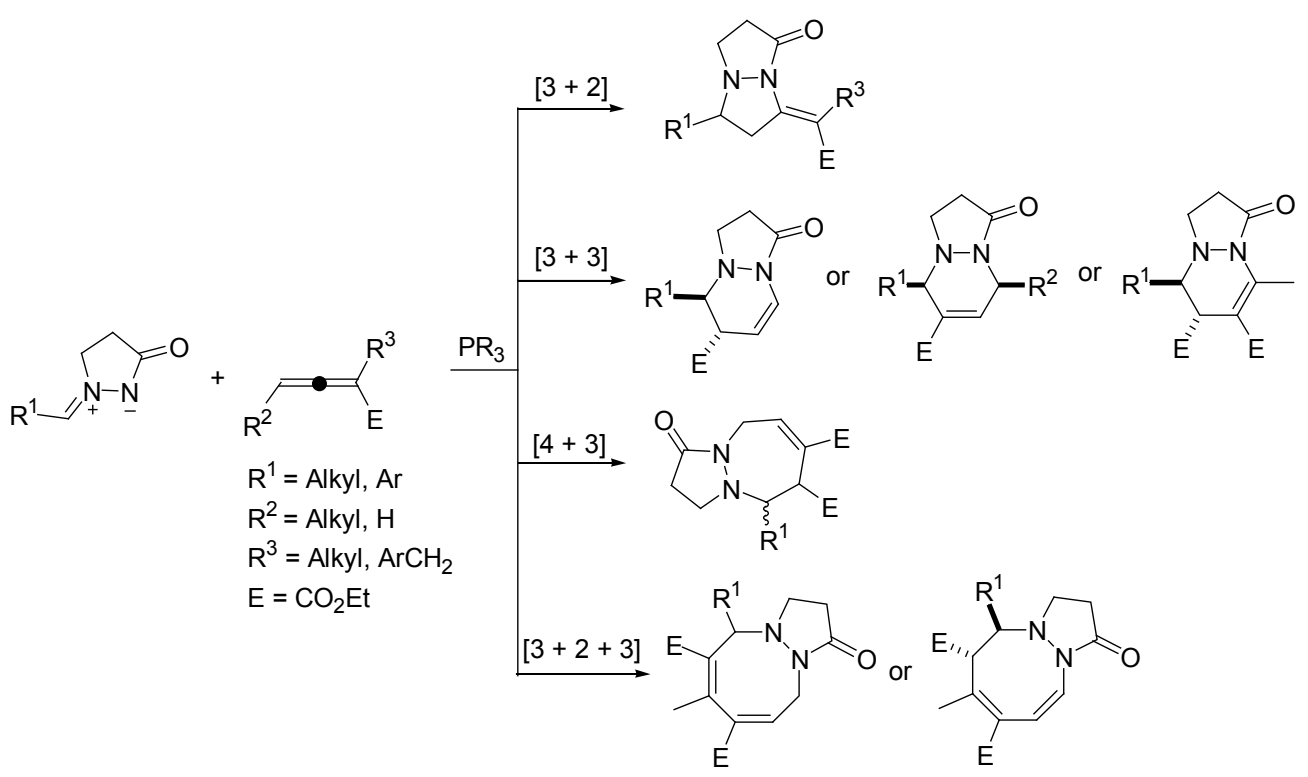

Scheme 13

\section{2 叔膦促进下 MBH 烯丙基化合物与亲电试剂 的环化反应类型}

近年来, 由 $\mathrm{MBH}$ 反应产物经过简单衍生所得到的 一系列烯丙基化合物，包括烯丙基卤代烃、烯丙基醋酸 酯以及烯丙基碳酸酯, 引起了人们广泛的研究兴趣. 这 类化合物在叔膦的作用下可以原位形成烯丙基磷叶立 德中间体(Scheme 14), 该中间体与叔膦对缺电子联烯亲 核加成所形成的两性离子中间体在结构上具有较大相 似之处, 并具有丰富的化学反应性, 能作为一种很好的 $\mathrm{C}_{3}$ 及 $\mathrm{C}_{1}$ 合成子, 与一系列亲电试剂发生多种类型的环 化反应.

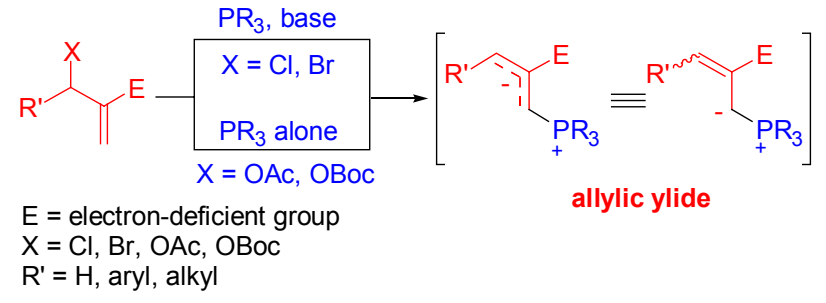

\section{Scheme 14}

2.1 叔膦促进下 $\mathrm{MBH}$ 烯丙基化合物与亲电试剂的[3+ n]环化反应

2003 年，陆熙炎等 ${ }^{[24]}$ 首次报道了 $\mathrm{MBH}$ 烯丙基化合 物与活化烯烃的 $[3+2]$ 环化反应. 研究发现, 在 10 
mol\%三苯基膦的催化下, 且 1.5 equiv. $\mathrm{K}_{2} \mathrm{CO}_{3}$ 存在的条 件下, 烯丙基溴化物及烯丙基醋酸酯与马来酰亚胺、 $\alpha, \beta$ 不饱和酮等活化烯烃能发生 $[3+2]$ 环化反应, 生成相应 的环戊烯衍生物; 而对于烯丙基碳酸酯，由于其可以在 叔膦的作用下原位生成叔丁氧基负离子, 因此不需要外 加碱就能发生该反应(Eq. 3). 作者提出的可能反应机理 如 Scheme 15 所示, 首先叔膦与烯丙基化合物作用, 经 过相应的转化原位生成烯丙基磷叶立德中间体 $\mathbf{4 2}$, 该中 间体以 $\alpha$-位碳负对活化烯烃亲核进攻得到中间体 $\mathbf{4 3 A}$, 随后发生分子内 Michael 加成及叔膦催化剂的消除, 得 到环化产物. 此外, 叶立德中间体 $\mathbf{4 2}$ 还能以 $\gamma$-位碳负对 活化烯烃亲核进攻, 经过相似的转化, 生成另一种少量 的区域异构产物.
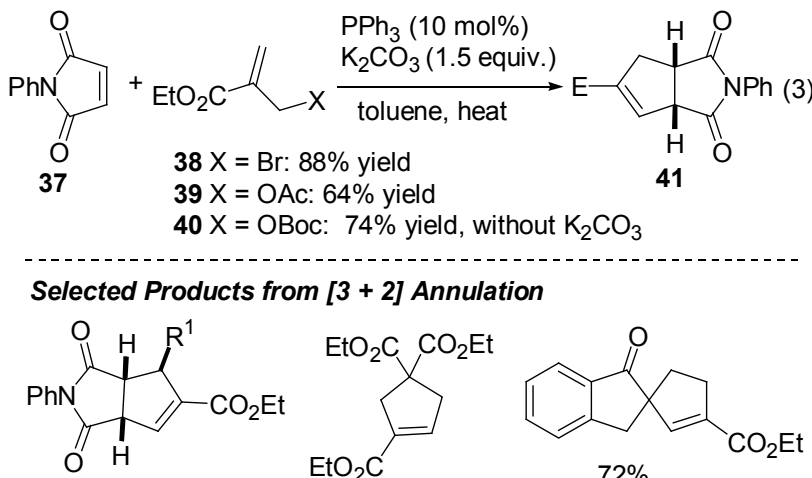

$\mathrm{R}^{1}=\mathrm{Ph}(68 \%)$, $n-\operatorname{Pr}(60 \%)$
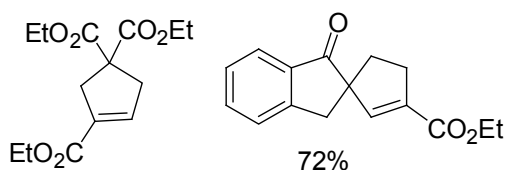

$72 \%$
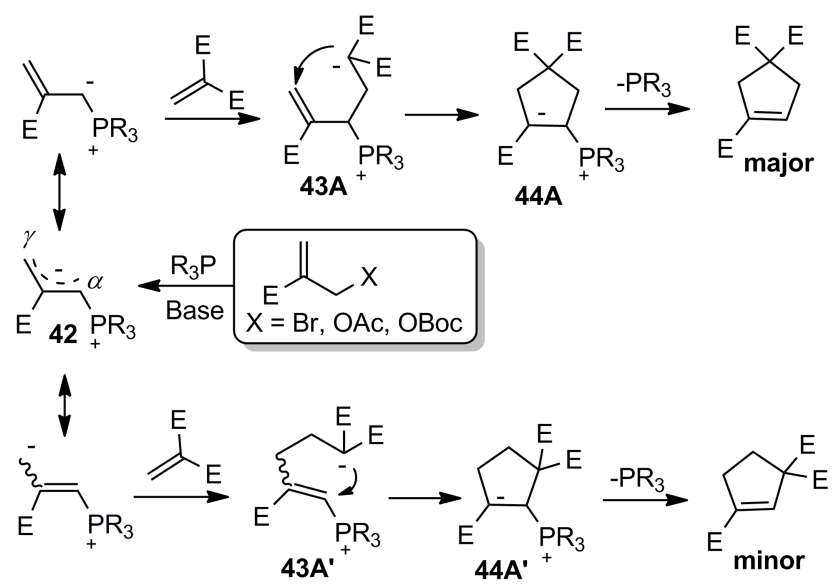

Scheme 15

随后，陆熙炎等对该反应的活化烯烃底物进行了进 一步的拓展, 实现了叔膦催化下, 烯丙基碳酸酯与双氯 基活化烯烃的 $[3+2]$ 环化反应, 高效合成了多取代的环 戊烯衍生物 ${ }^{[25]}$. 值得一提的是, 该反应取得了与上述 $[3$ +2]环化反应相反的区域选择性结果. 机理上, 由于叶 立德中间体的空间位阻不利于 $\alpha$-位碳负对活化烯烃亲 核进攻, 只能区域选择性地以 $\gamma$-位碳负对其加成, 从而
得到不同区域选择性的产物(Scheme 16).

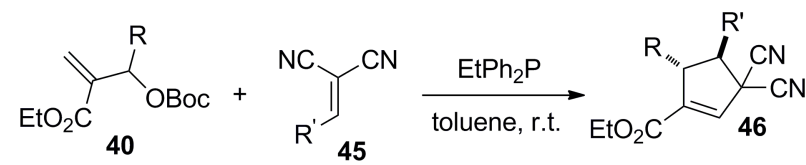

$\mathrm{R}=n-\mathrm{Pr}, i-\mathrm{Pr}, i-\mathrm{Bu}, 4-\mathrm{NO}_{2} \mathrm{C}_{6} \mathrm{H}_{4}$, 2-furyl

$\mathrm{R}^{\prime}=\mathrm{Ph}, 4-\mathrm{MeOC}_{6} \mathrm{H}_{4}$

up to $93 \%$ yield and 100:0 $d r$
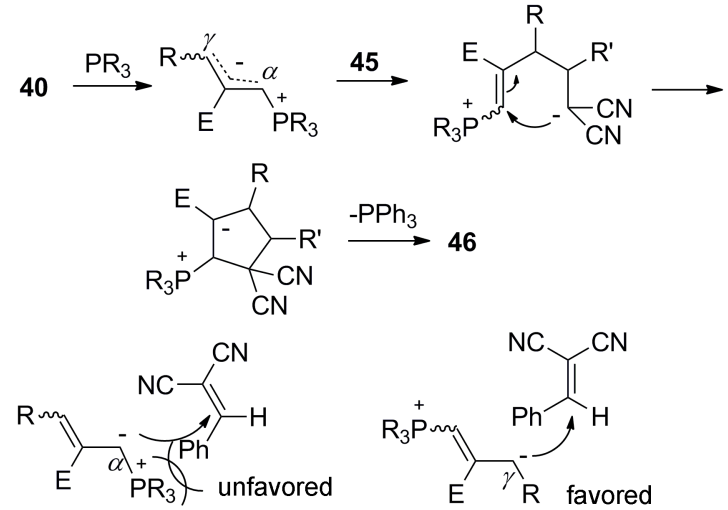

\section{Scheme 16}

陆熙炎等 ${ }^{[26]}$ 还发现，当双㲵基活化烯烃 $\beta$-位具有酸 性亚甲基时，则在叔膦催化下，与烯丙基碳酸酯发生了 $[3+3]$ 环化反应, 以较高的立体选择性生成多取代的环 己烯衍生物(Eq. 4). 机理研究表明, 该反应经过了一个 串联反应过程，首先在叔膦的催化下形成烯丙基烷基化 中间产物，随后再在叔膦的作用下经过一个碱催化的分 子内 Michael 加成反应过程, 得到最终产物.

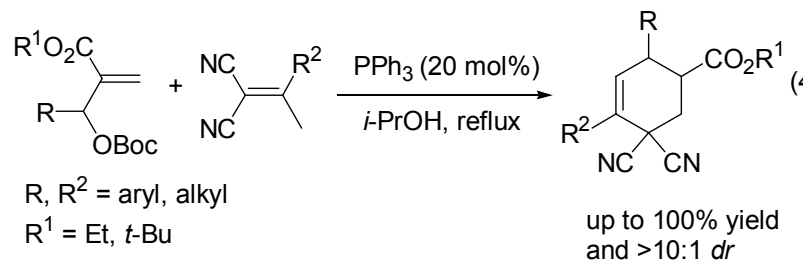

最近，施敏等 ${ }^{[27]}$ 以靛红衍生的双氰基活化烯烃为原 料，同样实现了与烯丙基碳酸酯的 $[3+2]$ 环化反应，以 较高的区域选择性及立体选择性合成了羟吲哚螺环戊 烯衍生物(Eq. 5). 同时，卢一新等 ${ }^{[28]}$ 利用天然氨基酸衍 生的双功能手性叔膦催化剂, Barbas 等 ${ }^{[29]}$ 利用手性双膦 催化剂, 分别完成了该反应的不对称转化, 并取得了优 秀的对映体选择性(Scheme 17). 值得一提的是, 上述由 氨基酸衍生的双功能手性叔膦催化剂具有优秀的催化 活性，将其结构稍作修饰，卢一新等 ${ }^{[30]}$ 还实现了烯丙基 碳酸酯与马来酰亚胺的不对称 $[3+2]$ 环化反应，以较高 的对映体选择性合成了双环环伐烯衍生物.

在实现了与活化烯烃的 $[3+2]$ 环化反应后，陆熙炎 等 ${ }^{[31}$ 研究发现, 磺酰亚胺同样能与烯丙基化合物发生 
<smiles>[R]C(OCC)C(=C)C(=O)OCC</smiles>

$\mathrm{R}^{1}=\mathrm{H}$, aryl, alkyl

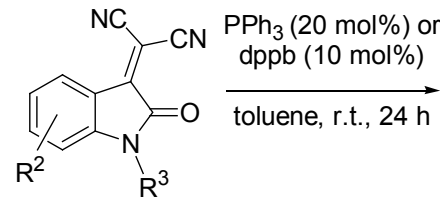

$\mathrm{R}^{2}=\mathrm{H}, \mathrm{Br}, \mathrm{Cl}, \mathrm{Me}$ $\mathrm{R}^{3}=\mathrm{Bn}$, allylic, $\mathrm{Me}$

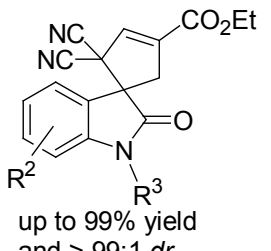
and > 99:1 dr
$[3+2]$ 环化反应(Scheme 18). 在 $10 \mathrm{~mol} \%$ 三苯基膦的催 化下，烯丙基碳酸酯与磺酰亚胺在甲苯中回流反应，能 以较高的收率生成二氢吡咯衍生物 48, 并且反应只得到 了单一区域选择性与立体选择性的产物. 有趣的是, 当 烯丙基碳酸酯上无取代基时 $(\mathrm{R}=\mathrm{H})$, 则与亚胺不再发生 $[3+2]$ 环化反应，而发生了一种新颖的串联反应，并且 能在更温和的条件下(常温摚拌)生成多官能团的链式产 物 47. 机理研究表明，当烯丙基碳酸酯上无取代基时 $(\mathrm{R}=\mathrm{H})$, 由于其具有更高的反应活性，因此优先被反应 中原位形成的烯丙基磷叶立德中间体进攻，随后再与亚 胺发生串联反应, 得到相应的链式产物(Scheme 19).

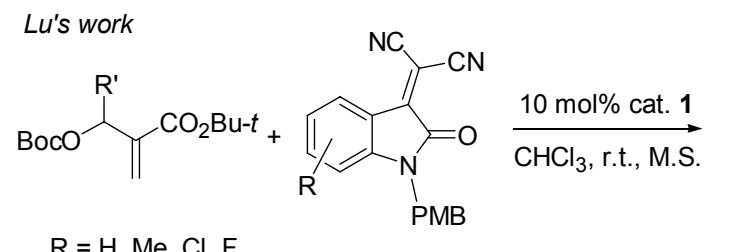
$\mathrm{R}=\mathrm{H}, \mathrm{Me}, \mathrm{Cl}, \mathrm{F}$
$\mathrm{R}^{\prime}=$ aryl<smiles>[R]c1cccc2c1N(P)C(=O)[C@]21C([R])C(C(=O)OCC)=CC1(C#N)C#N</smiles>

$65 \% \sim 96 \%$ ee dr 2:1 23:1 yield $82 \% \sim 96 \%$

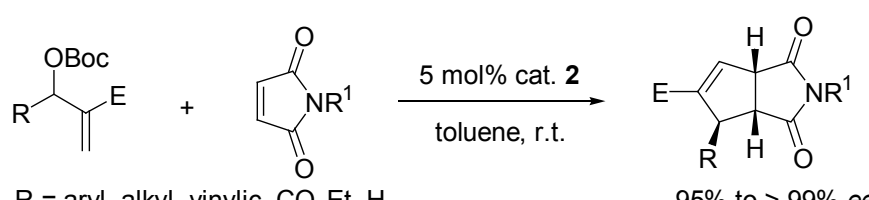

$\mathrm{R}=$ aryl, alkyl, vinylic, $\mathrm{CO}_{2} \mathrm{Et}, \mathrm{H}$

$95 \%$ to $>99 \%$ ee yield $88 \% \sim 98 \%$

\section{Barbas's work}

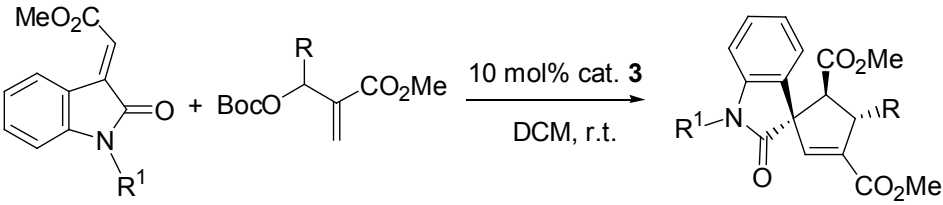

$\mathrm{R}=$ alkyl, aryl

$\mathrm{R}^{1}=$ Boc, $N$-phenylacetyl

$71 \% \sim 99 \%$ ee<smiles>CCC(C)C(Cc1ccccc1)NC(=S)Nc1ccc(F)cc1</smiles>


yield $47 \% \sim 91 \%$

Scheme 17
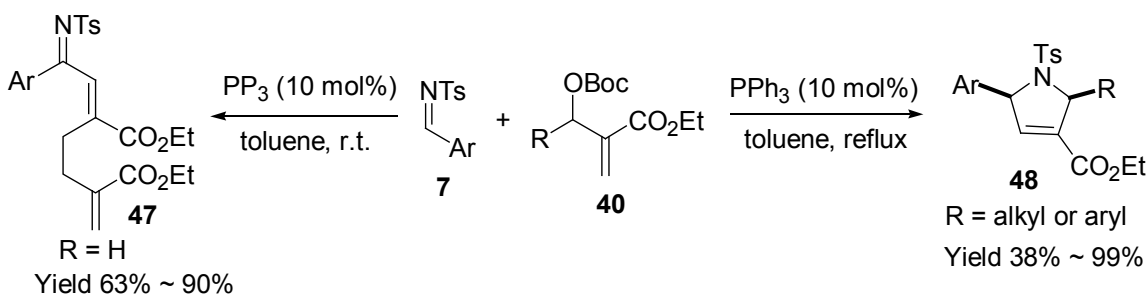

Scheme 18 


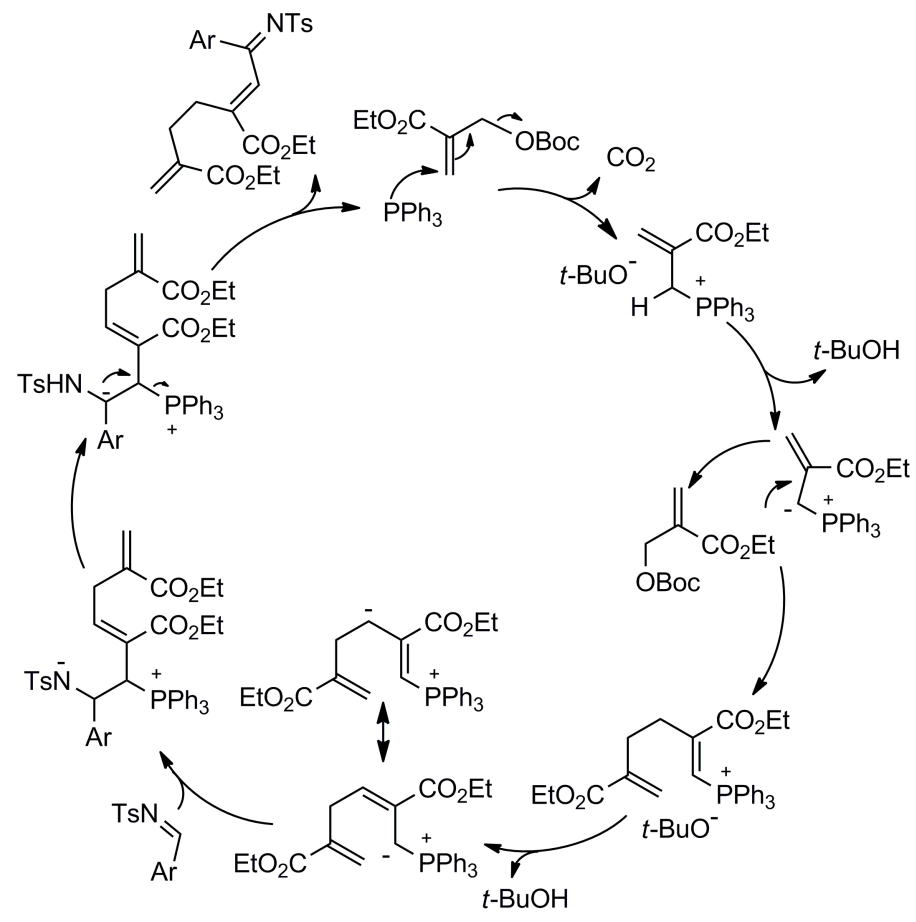

Scheme 19

在报道了烯丙基化合物的 $[3+2]$ 环化反应后, 陆熙 炎等 ${ }^{[32]}$ 发现, 其还可以与托品酮发生 $[3+6]$ 环化反应. 在叔膦的催化下及 $\mathrm{K}_{2} \mathrm{CO}_{3}$ 存在的条件下, 烯丙基澳代 烃、烯丙基氯代烃、烯丙基醋酸酯及烯丙基碳酸酯, 可 以顺利地与托品酮 49 发生 $[3+6]$ 环化反应, 生成桥环化 合物 50 (Scheme 20). 反应机理如 Scheme 20 所示, 叔膦 与烯丙基化合物作用原位形成烯丙基磷叶立德中间体 42, 该中间体以 $\alpha$-位或 $\gamma$-位碳负离子对托品酮亲核进攻 得到中间体 51, 随后经过分子内 Michael 加成及叔膦催 化剂的消除, 生成环化产物 $\mathbf{5 0}$. 由于 $\alpha$-位或 $\gamma$-位碳负

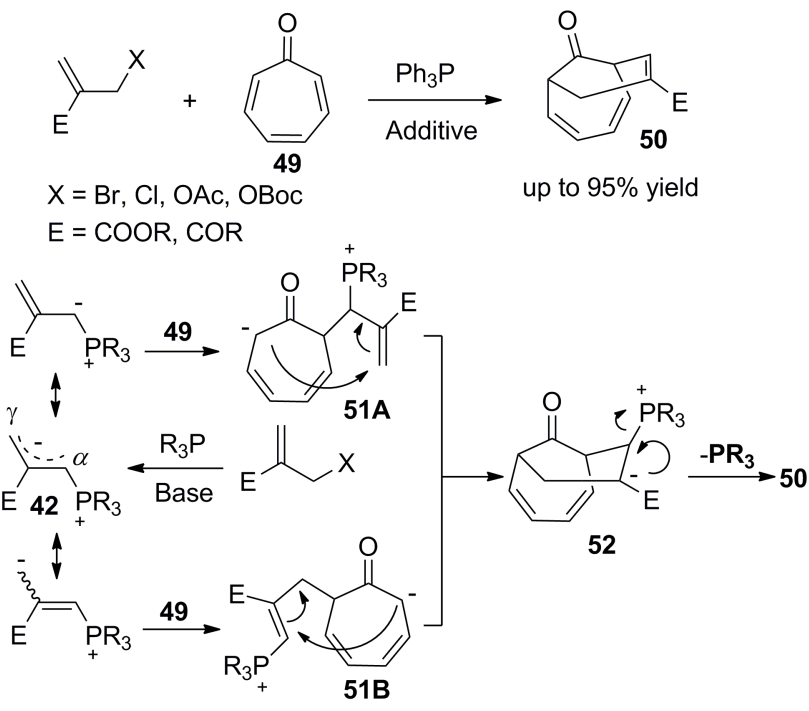

Scheme 20
离子对托品酮亲核进攻所形成的产物构型相同，因此这 两种反应方式都存在可能性.

2009 年，陆熙炎等 ${ }^{[33]}$ 报道了叔膦催化下，烯丙基碳 酸酯与香豆灵酸酯的 $[3+4]$ 环化反应，高度区域选择性 地合成了双环 [3.2.2]壬二烯衍生物(Eq. 6). 机理上，首 先叔膦与烯丙基碳酸酯作用, 经过一个加成-消除-去质 子的过程，原位生成烯丙基磷叶立德中间体 42, 随后以 $\gamma$-位碳负对香豆灵酸酯亲核加成得到中间体 $\mathbf{5 5}$, 接着发 生分子内 Michael 加成及叔膦的消除, 得到环化产物 54 . 对于反应所取得的高度区域选择性，作者认为主要归功 于基团的空间效应. 一方面, 烯丙基磷叶立德只能以 $\gamma$ 位碳负 42B 对香豆灵酸甲酯亲核进攻, 另一方面, 在随 后的分子内 Michael 加成反应中, 只能以 55B 的模式进 行(Scheme 21).

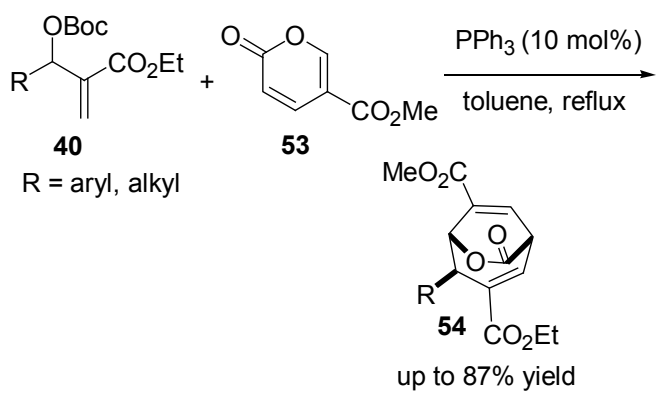

(6)

最近，本课题组报道了叔膦催化下，烯丙基碳酸酯 与 $\alpha, \beta$-不饱和酮的串联 $[3+2]$ 环化一烯丙基烷基化、 $[2+$

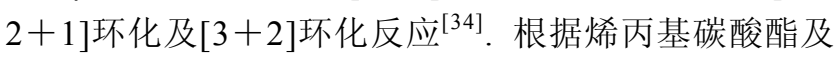




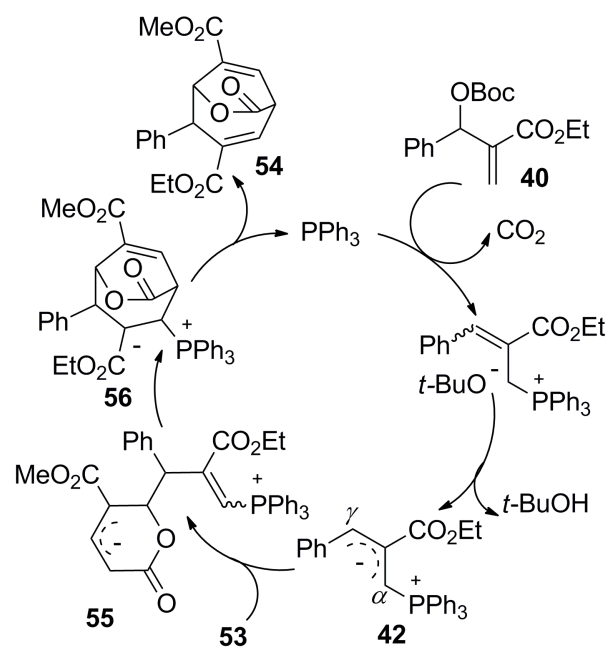

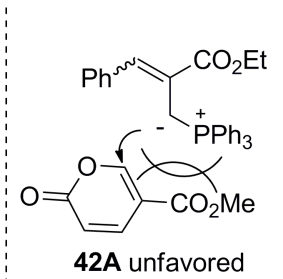<smiles>CCOC(=O)c1ccccc1/C=C(\CC)c1ccccc1</smiles>

\section{Scheme 21}

$\alpha, \beta$-不饱和酮上取代基结构的不同, 上述反应可以化学 选择性地发生, 得到高度官能团化的环戊烯及环戊烷衍 生物(Scheme 22). 当烯丙基碳酸酯上取代基 $\mathrm{R}^{1}$ 为 $\mathrm{H}$ 时, 由于其具有较高的反应活性, 主要发生串联 $[3+2]$ 环 化-烯丙基烷基化反应; 在此条件下, 当 $\alpha, \beta$-不饱和酮上 的芳基 $\mathrm{Ar}^{2}$ 连有强拉电子基团(如硝基)时, 则主要发生 $[2+2+1]$ 环化反应; 当烯丙基碳酸酯上取代基 $\mathrm{R}^{1}$ 为芳 基时, 则主要发生 $[3+2]$ 环化反应. 值得一提的是, 在 $[2+2+1]$ 环化反应中, 所生成的环戊烷衍生物具有五 个连续的手性中心, 并且其中三个连续基团都处于环的 同侧, 由于基团间的空间位阻, 这在合成化学中并不多 见.

机理探究实验发现，在相同的反应条件下，[3+2] 环化反应产物 60a 能顺利地转化为 $[3+2]$ 环化-烯丙基 烷基化反应产物 58a (Scheme 23). 针对实验结果, 我们 提出了可能的反应机理: 叔膦对烯丙基碳酸酯亲核进 攻, 经过一个加成-消除-去质子的过程得到叶立德 $\mathbf{4 2}$, 42 以 $\gamma$-位碳负对 $\alpha, \beta$-不饱和酮亲核加成得到中间体 61 . 当 $\mathrm{R}^{1}$ 为芳基时, 61 经过分子内 Michael 加成及膦的消去, 得到 $[3+2]$ 环化产物 60; 当 $\mathrm{R}^{1}$ 为 $\mathrm{H}$, 同时 $\alpha, \beta$-不饱和酮 具有较高的活性时(芳环上带有强拉电子基团), 61 对另
一分子 $\alpha, \beta$-不饱和酮亲核进攻得到 65,65 经过双键迁移 得到 66, 66 经 $\mathrm{S}_{\mathrm{N}} 2^{\prime}$ 反应离去膦催化剂, 得到 $[2+2+1]$ 环 化产物 59; 当 $\mathrm{R}^{1}$ 为 $\mathrm{H}$, 同时 $\alpha, \beta$-不饱和酮不具有较高活 性时(芳基上不带强拉电子基团), 61 发生分子内 Michael 加成得到 63,63 对另一分子烯丙基碳酸酯亲核进攻得到 64, 64 经过脱质子及膦的消除, 得到 $[3+2]$ 环化一烯丙基 烷基化产物 $\mathbf{5 8}$ (Scheme 23).

\section{2 叔膦促进下 $\mathrm{MBH}$ 烯丙基化合物与亲电试剂的 $[1+$ 4]环化反应}

在叔膦催化下, 烯丙基化合物除了作为 $C_{3}$ 合成子, 参与 $[3+\mathrm{n}]$ 环化反应, 还可以用作 $C_{1}$ 合成子, 参与 $[1+$ 4]环化反应. 2010 年, 张俊良教授 ${ }^{[35]}$ 首次报道了叔膦催 化下, 烯丙基碳酸酯与 $\alpha, \beta$-不饱和酮的 $[1+4]$ 环化反应, 以高度的区域选择性与立体选择性合成了多取代的二 氢呋喃衍生物(Scheme 24). 结合前述 $[3+2]$ 环化反应机 理，作者提出了如下反应机制，首先叔膦与烯丙基碳酸 酯作用，原位生成烯丙基磷叶立德中间体 42, 受基团空 间位阻的影响，该中间体区域选择性地以 $\gamma$-碳负对 $\alpha, \beta$ 不饱和酮 67 亲核进攻, 生成烯醇负离子 69 , 随后发生 1,3-氢迁移得到中间体 70, 70 经分子内 $\mathrm{S}_{\mathrm{N}} 2^{\prime}$ 反应得到环 化产物 68, 并消除膦催化剂.



Scheme 22 

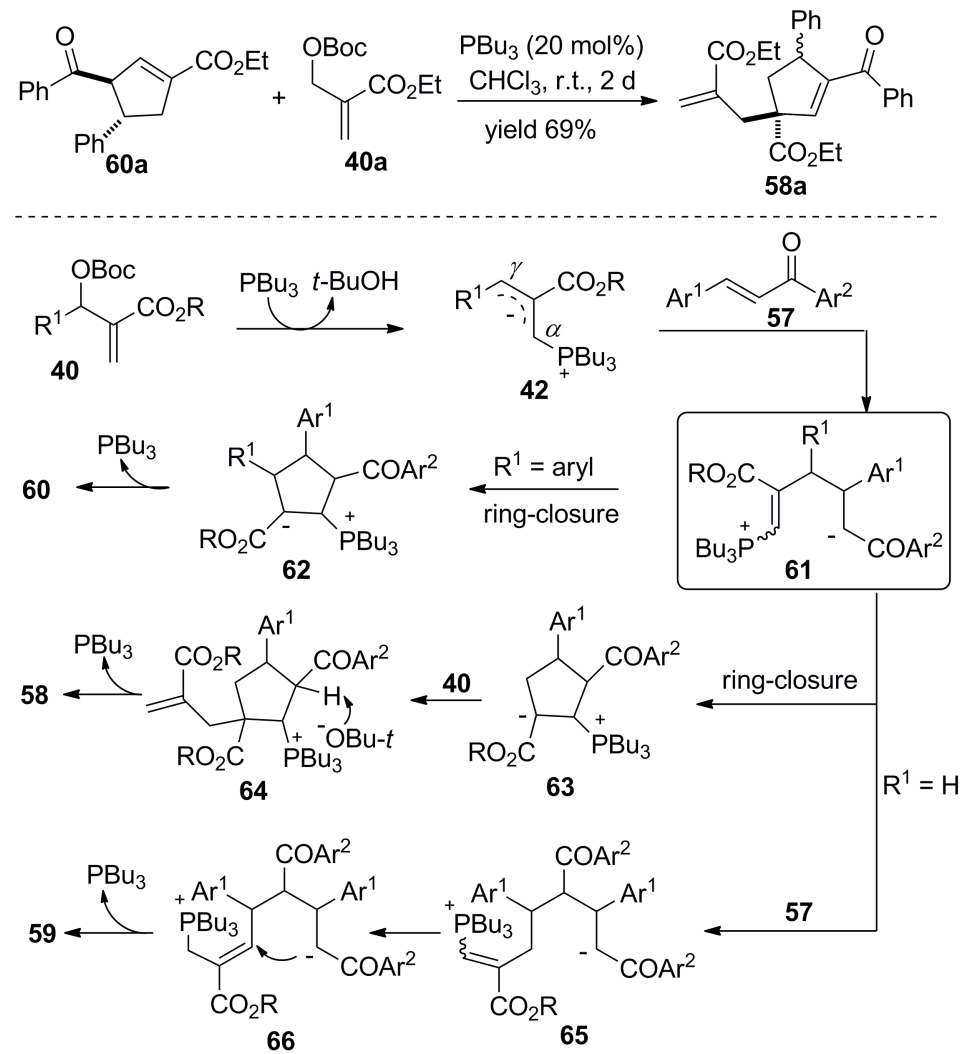

Scheme 23

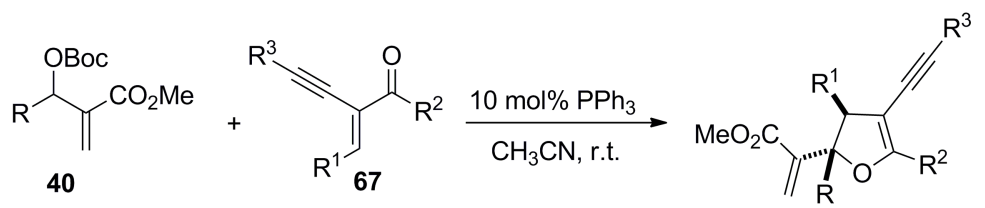

$\mathrm{R}^{1}, \mathrm{R}^{2}, \mathrm{R}^{3}=$ aryl, alkyl

68

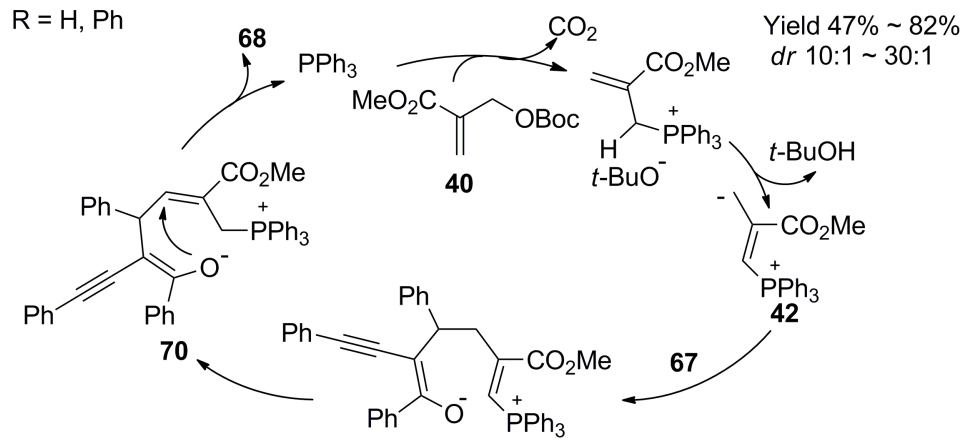

69

Scheme 24

最近, 本课题组 ${ }^{[36]}$ 研究发现, $\alpha, \beta$-不饱和亚胺同样 可以与烯丙基碳酸酯发生 $[1+4]$ 环化反应, 高度立体选 择性地生成二氢吡咯衍生物(Scheme 25). 需要说明的 是, 在我们的研究中, 只有无取代的烯丙基碳酸酯才能 发生 $[1+4]$ 环化反应，对于芳基取代的烯丙基碳酸酯则 与 $\alpha, \beta$-不饱和亚胺发生 $[3+2]$ 环化反应. 此外, 研究还 发现 ${ }^{[37]}$, 在三芳基膦的催化下, 双活化硝基烯烃可以与
烯丙基碳酸酯发生 $[1+4]$ 环化反应，高度立体选择性地 生成多取代异噁唑啉氮氧化合物(Eq. 7). 该反应具有较 宽的底物适用范围，对于无取代及芳基取代的烯丙基碳 酸酯都能发生 $[1+4]$ 环化反应，同时芳基及烷基取代的 硝基烯也能顺利地发生该反应. 有趣的是，当烯丙基碳 酸酯上无取代基时, 主要得到反式的环化产物, 而当烯 丙基碳酸酯上取代基为芳基时，则主要得到顺式的环化 


$$
\text { Boc=tert-butoxycarbonyl }
$$

Scheme 25
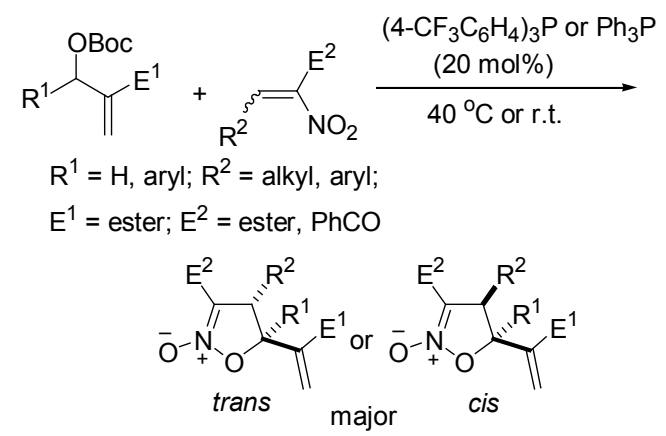

Yield $39 \% \sim 97 \%$

dr 5:1 20:1

产物. 值得一提的是, 异噁唑啉氮氧化合物广泛存在于 天然产物及药物分子中, 并是一类重要的有机合成中间 体, 经过简单的衍生, 可以转化为氨基醇、氨基酸、异 噁唑啉等重要的有机分子 ${ }^{[37]}$.

黄有等 ${ }^{[38]}$ 研究发现, 在叔膦催化下, 烯丙基碳酸酯 与硫代磷酰基水杨亚胺可以发生 $[1+4]$ 环化反应, 以较 高的收率及立体选择性生成苯并二氢呋喃衍生物 (Scheme 26). 反应机理如 Scheme 26 所示, 叔膦与烯丙 基碳酸酯作用原位形成烯丙基磷叶立德中间体 42, 随后 以 $\gamma$-位碳负对水杨亚胺 71 亲核加成得到 73, 73 经过双 键迁移形成 74, 质子转移后得到 75 , 最后发生分子内 $\mathrm{S}_{\mathrm{N}} 2^{\prime}$ 反应得到产物 72 并释放叔膦催化剂.

有关 $[1+4]$ 环化反应的不对称转化, 最近也得到了 较好的发展. 施敏等 ${ }^{[39]}$ 利用具有联萗骨架的双功能手性 叔膦催化剂, 实现了烯丙基碳酸酯与 1,1-双氭基共轭二 烯烃 ${ }^{[39 a]}$ 及靛红衍生的 $\alpha, \beta$-不饱和酮 ${ }^{[39 b]}$ 的 $[1+4]^{\text {环化反 }}$
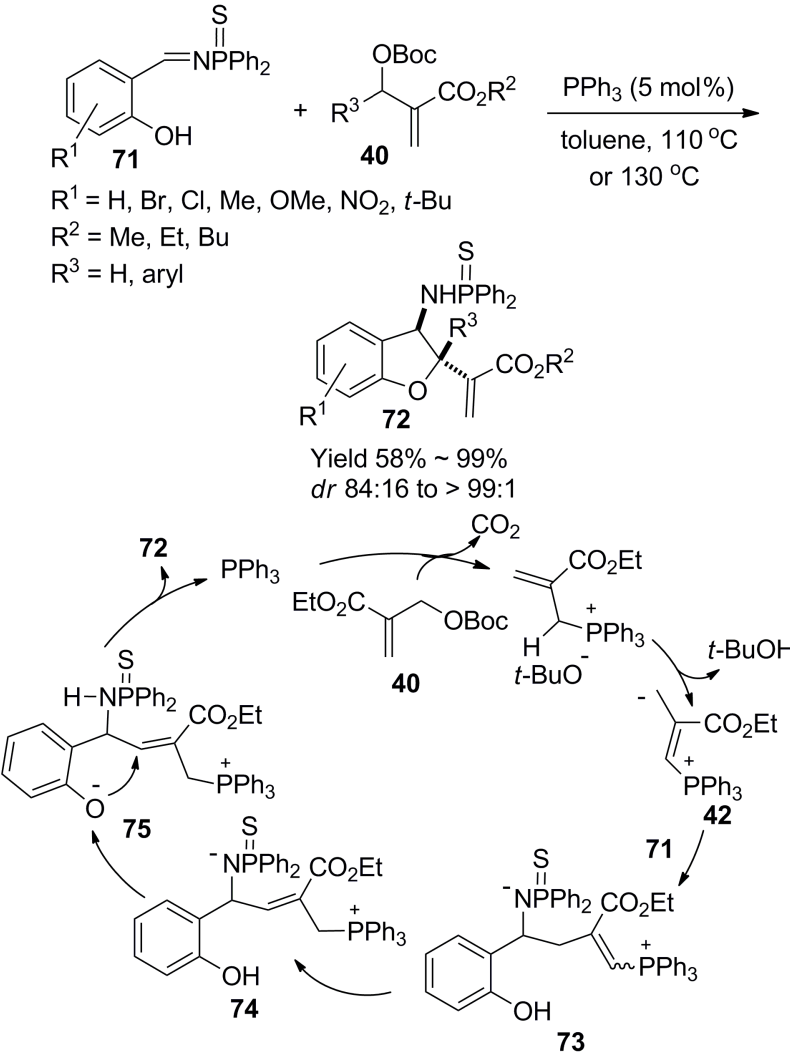

Scheme 26

应，以较高的收率及优秀的对映体选择性合成了多取代 的环戍烯衍生物(Scheme 27).

\section{3 叔膦促进下 $\mathrm{MBH}$ 烯丙基化合物与亲电试剂的其他 环化反应}

在叔膦促进下，烯丙基化合物与亲电试剂不仅能发 生 $[3+n]$ 及 $[1+4]$ 环化反应, 还可以发生其他类型环化 反应. 黄有课题组在这一领域做出了代表性的研究工 作，2012 年，该小组 ${ }^{[40]}$ 报道了叔膦促进下烯丙基碳酸酯 与芐叉基丙酮酸酯的串联环化一芳香化反应. 在当量 $\mathrm{PPh}_{3}$ 的促进下，烯丙基碳酸酯 40 与芐叉基丙酮酸酯 76 在 DMSO 中于 $120{ }^{\circ} \mathrm{C}$ 的条件下反应，能以较高收率生 成多取代的苯或联苯衍生物 77 (Eq. 8). 作者认为反应 存在两种可能机制(Scheme 28), 首先叔膦与烯丙基碳酸 酯作用原位生成磷叶立德中间体 42, 该中间体可以进攻 芐叉基丙酮酸酯 76 的 $\mathrm{C}=\mathrm{C}$ 键，生成烯醇负离子中间体 78, 随后经氢迁移形成叶立德中间体 79, 79 发生分子内 Wittig 反应得到环已二烯 $\mathbf{8 0}$, 最后经空气中氧促进的芳 香化过程得到反应产物 77 (Path A); 此外, 叶立德中间 体 42 可以直接与苠叉基丙酩酸酯 76 发生 Wittig 反应, 得到中间体 81, 81 经过 $6 \pi$ 电环化过程得到环已二烯 82 , 最后同样经氧促进的芳香化过程得到反应产物 77 (Path B). 

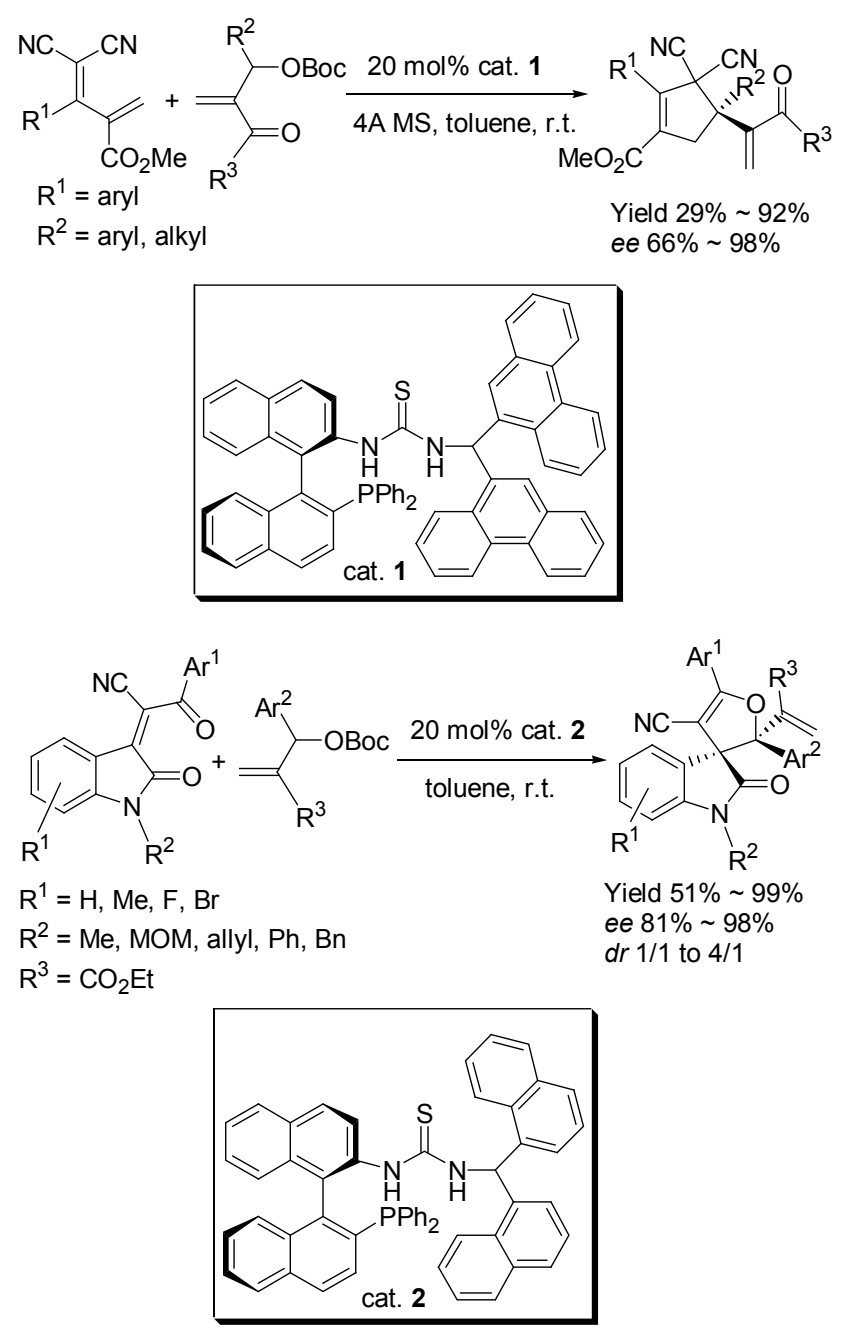

Scheme 27

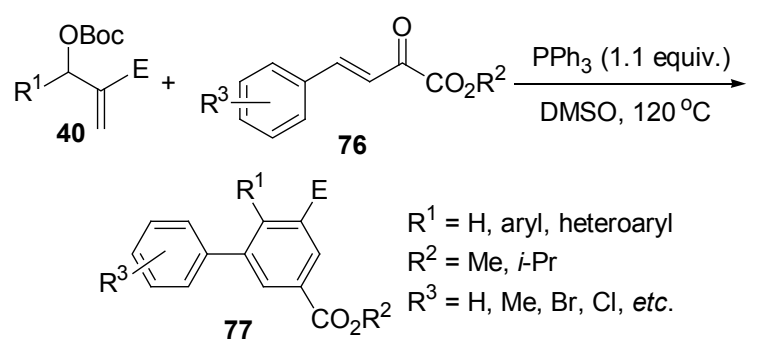

Yield $30 \% \sim 85 \%$

值得一提的是，目前过渡金属催化卤代芳烃的偶联 反应是合成联苯型化合物的一种有效方法, 但这一方法 在合成卤素取代的联苯型化合物时往往具有较低的选 择性，然而采用上述反应策略，当反应底物烯丙基碳酸 酯或芐叉基丙酩酸酯的芳环上有卤素取代基时，卤素原 子在产物中得以保留, 从而可以高效地合成卤素取代的 联苯型化合物, 因此该方法较好地弥补了过渡金属催化 卤代芳烃偶联反应的不足.

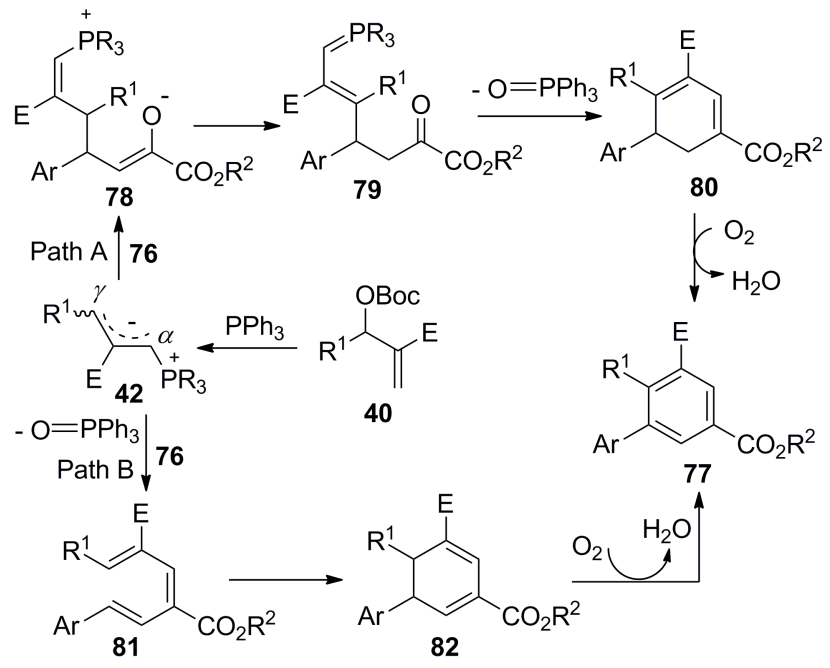

Scheme 28

研究还发现, 控制叔膦的用量, 可以改变上述反应 的化学选择性, 当采用催化量的叔膦时, 主要得到 $[1+$ 4]环化产物, 而采用化学计量的叔膦时, 则主要生成串 联环化一芳香化产物, 并且研究还证实反应所生成的 $[1+4]$ 环化产物在当量叔膦的促进下可以转化为相应的 芳香烃产物 ${ }^{[41]}$.

最近，该小组 ${ }^{[22]}$ 报道了对氟三苯基膦催化下烯丙基 碳酸酯与磺酰基活化的 1,3-二烯烃的串联环化反应，立 体选择性地合成了双环 [4.1.0]庚烯衍生物(Scheme 29). 机理上，反应首先由叔膦与烯丙基碳酸酯原位形成磷叶 立德中间体 42, 随后对 1,3-二烯烃 83 亲核进攻得到中间 体 85,85 经分子内 Michael 加成形成 86 , 氢迁移后得 87 , 最后发生分子内 $\mathrm{S}_{\mathrm{N}} 2$ 反应生成环化产物 84 并离去膦催 化剂.
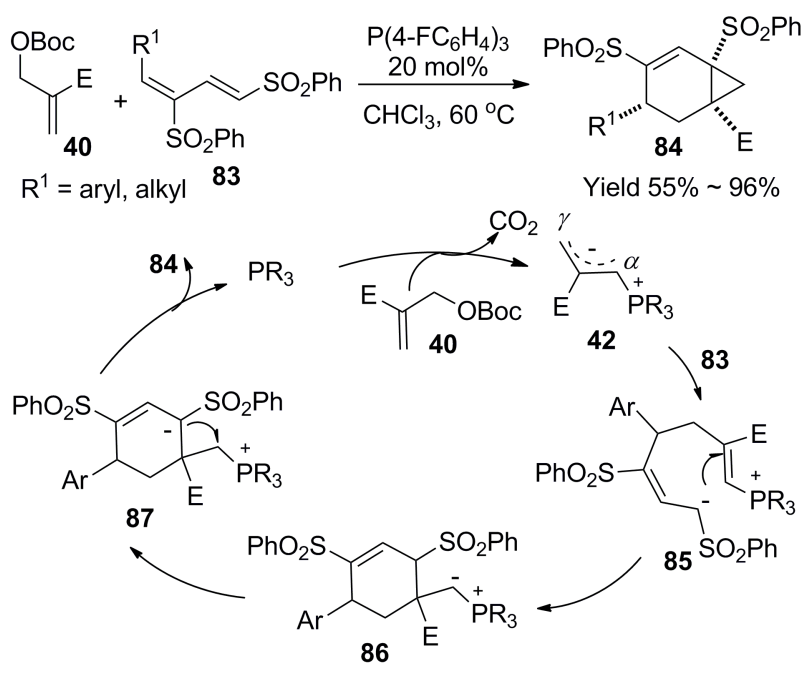

Scheme 29

综上所述，在叔膦的促进下，MBH 烯丙基化合物原 位生成的烯丙基磷叶立德具有丰富的化学反应性，与不 
同亲电试剂作用，可以完成多种类型的环化反应. 目前 广为报道的反应包括其作为三碳合成子参与的 $[3+n]$ 环 化反应以及作为一碳合成子参与的 $[1+4]$ 环化反应, 相 信随着研究工作的深入, 其他新的环化反应类型还会不 断被发现.

\section{3 叔膦促进下缺电子烯烃与亲电试剂的环化反 应类型}

缺电子烯烃在叔膦的亲核进攻下可以形成活性较 高的两性离子中间体(Eq.9), 该中间体具有丰富的化学 反应性，能与多种亲电试剂发生反应，如 Rauhut-Currier 反应 ${ }^{[33]}$ 及 Morita-Baylis-Hillman 反应 ${ }^{[44]}$ 等. 近年来, 基 于此两性离子的环化反应也得到了快速发展, 并涌现了 大量高效的合成新方法. 叔膦促进下缺电子烯烃与亲电 试剂的环化反应, 大都经历了一个串联反应过程. 首先 叔膦对缺电子烯烃亲核进攻, 得到亲核性负离子, 所生 成的负离子中间体对亲电试剂进行加成, 再经过多步串 联, 得到最终环化产物. 因此反应要顺利进行, 底物缺 电子烯烃与亲电试剂的活性必须有一定差异, 首先缺电 子烯烃与叔膦能形成具有一定稳定性的亲核性负离子 (如烯醇负离子), 其次亲电试剂能作为 Michael 受体顺 利捕获到上述负离子, 发生后续反应. 在已报道的环化 反应中, 缺电子烯烃一般为能形成烯醇负离子的 $\alpha, \beta$-不 饱和羰基化合物, 而亲电试剂则可以是活化烯烃、亚胺 等.

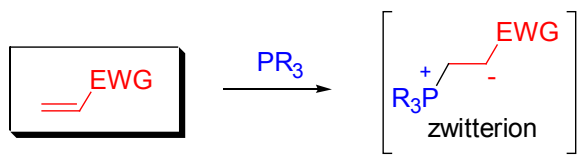

(9)

\section{1 叔膦促进下缺电子烯烃与活化烯烃的环化反应}

2011 年, 本课题组 ${ }^{[45]}$ 报道了叔膦催化下两种不同
活化烯烃的 $[2+2+2]$ 及 $[2+2+1]$ 环化反应. 在 $10 \mathrm{~mol} \%$ $\mathrm{PPh}_{3}$ 的催化下, $\alpha, \beta$-不饱和酮 88 与双活化烯烃 89 在 1,4二氧六环溶液中能发生 $[2+2+2]$ 环化反应，以高度的 立体选择性生成多取代环已烷衍生物 90 (Scheme 30); 有趣的是，当采用 $\mathrm{PBu}_{3}$ 作为催化剂时，同样的反应底物 则发生了 $[2+2+1]$ 环化反应，得到环戊烯衍生物 91. 根 据膦催化剂的不同, 两种环化反应可以化学选择性地发 生. 基于上述实验结果，我们提出了如下的反应机理 (Scheme 31): 叔膦对 $\alpha, \beta$-不饱和酮 88 亲核进攻, 生成烯 醇负离子中间体 92, 92 对双活化烯烃亲核加成生成中间 体 93, 随后再与另一分子活化烯烃加成，得到中间体 94, 当催化剂为离去能力较好的 $\mathrm{PPh}_{3}$ 时, 94 发生分子内 $\mathrm{S}_{\mathrm{N}} 2$ 反应，生成 $[2+2+2]$ 环化产物 90 并离去叔膦催化 剂; 当催化剂为离去能力较差的 $\mathrm{PBu}_{3}$ 时, 94 经氢迁移生 成叶立德中间体 96, 随后发生分子内 $\mathrm{S}_{\mathrm{N}} 2$ 反应，离去稳 定性较好的丙二腈或氰基乙酸甲酯负离子，生成中间体 97, 97 在丙二腈或氰基乙酸甲酯负离子作用下发生 E2 消除, 得到 $[2+2+1]$ 环化产物 91 并离去叔膦催化剂. 在机理研究中, 我们首次提出叔膦离去能力的不同导致 反应化学选择性的差别, 充分体现了叔膦对反应强大的 调控能力

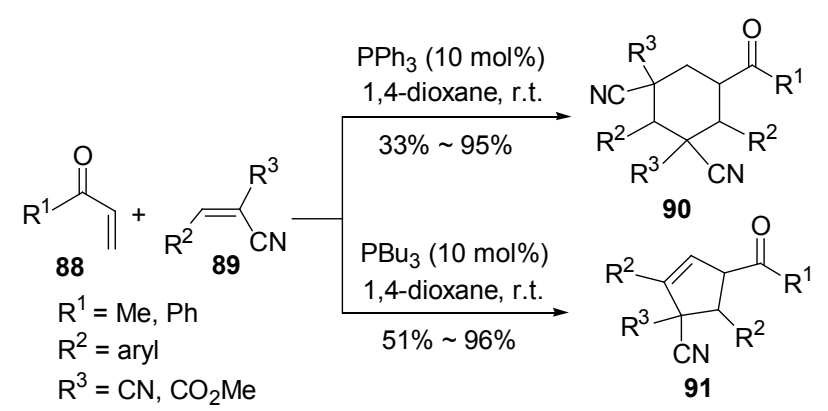

Scheme 30

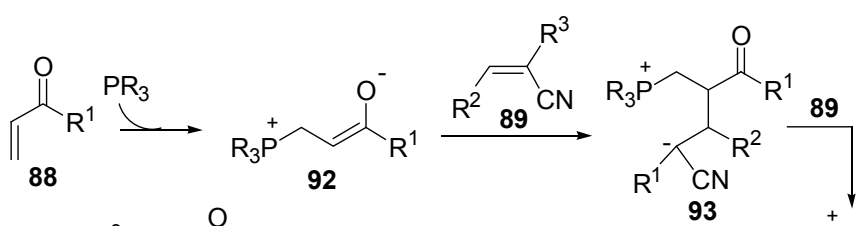

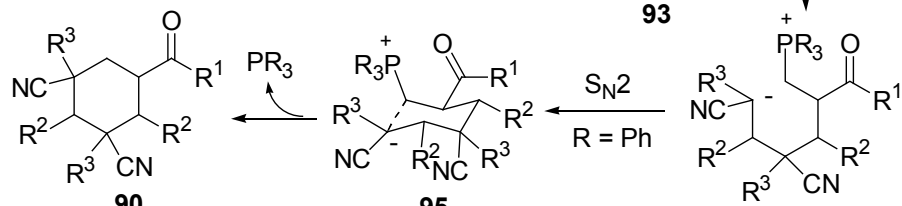

90

95<smiles>[R]C(=O)C1C=C([R])C([R3])(C#N)C1[R]</smiles><smiles>[R]C(=O)C1C([R7])C([R2])([R])C([R])(N)C1[R]</smiles>

94

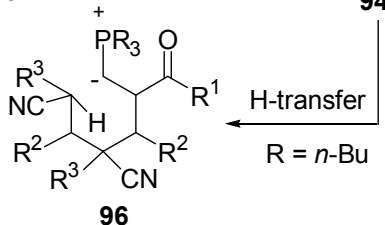

Scheme 31 
随后，本课题组 ${ }^{[46]}$ 报道了叔膦催化下，1,4-二烯-3酮与双氧基活化烯烃的 $[4+2]$ 环化反应，以较高的原子 经济性及立体选择性合成了环已酮衍生物(Scheme 32). 机理上, 反应同样起始于叔膦对 1,4-二烯-3-酮的亲核进 攻, 所形成的烯醇负离子 101 再与双氧基活化烯烃进行 $[4+2]$ 环化反应. 值得一提的是, 该 $[4+2]$ 环化产物经过 简单衍生, 可以转化成一类具有潜在生物活性的桥环化 合物, 从而较好地证明了该反应在有机合成中的用途 (Scheme 33).

最近, 施敏等 ${ }^{[47]}$ 采用含联荎骨架的双功能手性叔膦 催化剂, 实现了 1,4-二烯-3-酮与靛红衍生的双氧基活化 烯烃的不对称 [4+2]环化反应, 以优秀的非对映体选择 性与对映体选择性合成了羟吲哚螺环已酩衍生物(Eq. 10). 机理探索实验证明, 反应经过了 $\mathrm{RC} / \mathrm{Michael} / \mathrm{RC}$ 的 串联过程.
2013 年, 本课题组 ${ }^{[48]}$ 报道了 $(p \text {-toyl })_{3} \mathrm{P}$ 催化下 $\alpha, \beta$ 不饱和酮与马来酰亚胺的高度化学选择性 RauhutCurrier 反应，并实现了 $(p \text {-toyl })_{3} \mathrm{P}$ 催化的分子间 $\mathrm{RC}$ 反应 与 $\mathrm{PBu}_{3}$ 参与的分子内 $\mathrm{Wittig}$ 反应的串联过程，高效合成 了双环环戊烯衍生物(Scheme 34). 有趣的是, 当采用具 有环外双键的 $\alpha, \beta$-不饱和酮反应底物时, 经过串联反应 过程后, 能以高度的立体选择性得到多环化合物 (Scheme 35). 通过一系列机理探究实验, 我们提出了合 理的反应机制(Scheme 36), 叔膦对马来酰亚胺 104 亲核 进攻，生成烯醇负离子 108 , 一方面在质子性添加剂 $\mathrm{PhCO}_{2} \mathrm{H}$ 的作用下, 108 通过可逆氢迁移能形成稳定的磷 叶立德 109, 另一方面 108 可以对 $\alpha, \beta$-不饱和酮 105 进行 亲核加成, 形成中间体 110 , 当采用离去能力较好的三 芳基膦催化剂时, 110 经氢迁移得到中间体 111, 随后发

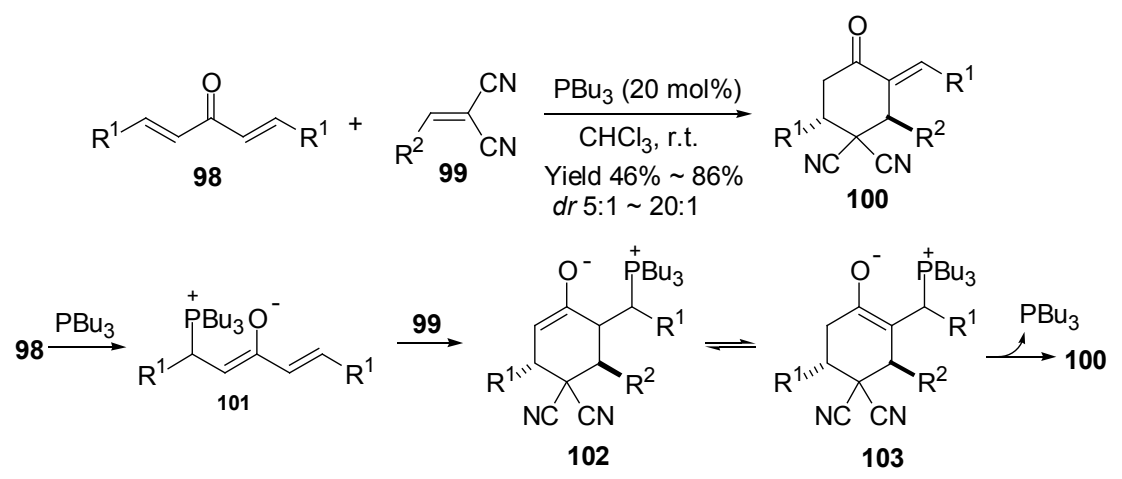

Scheme 32
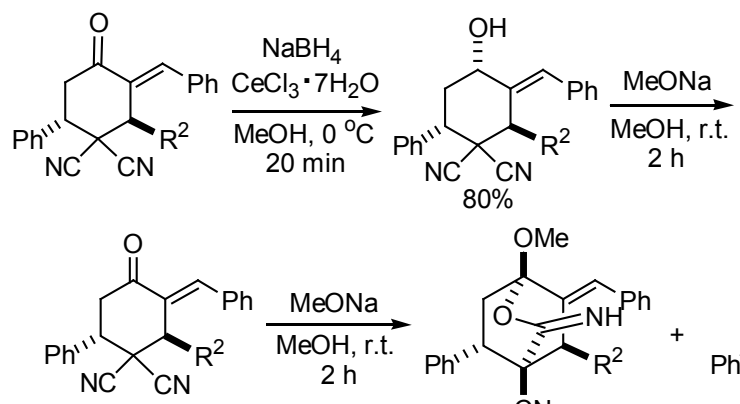

$\mathrm{R}^{2}=4-\mathrm{ClC}_{6} \mathrm{H}_{4}$
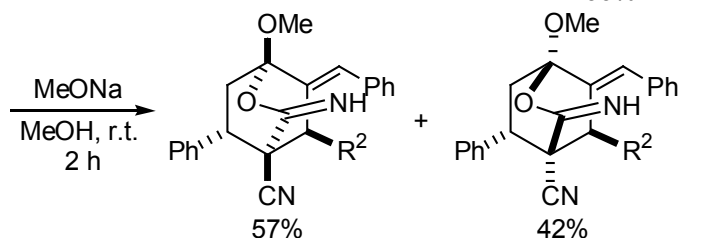

Scheme 33
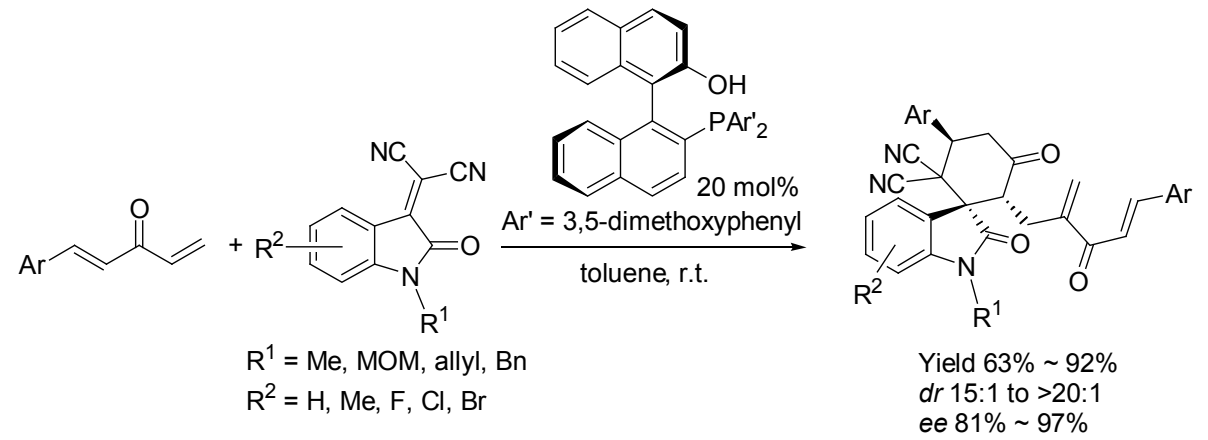


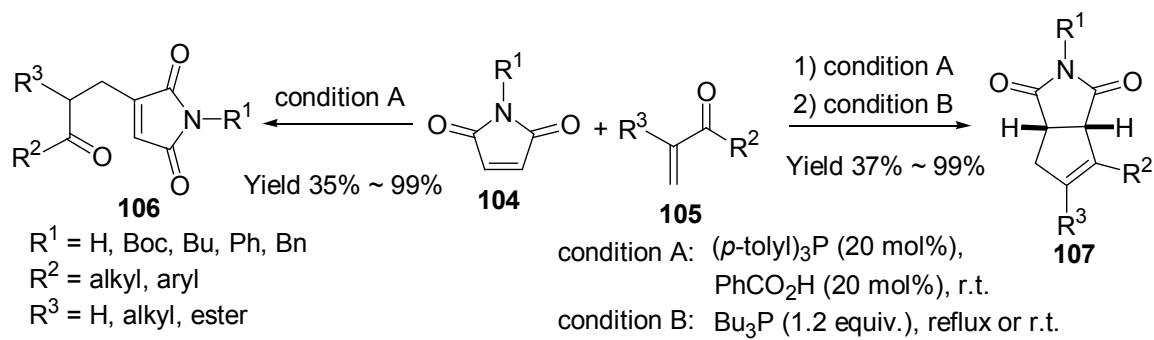

Scheme 34

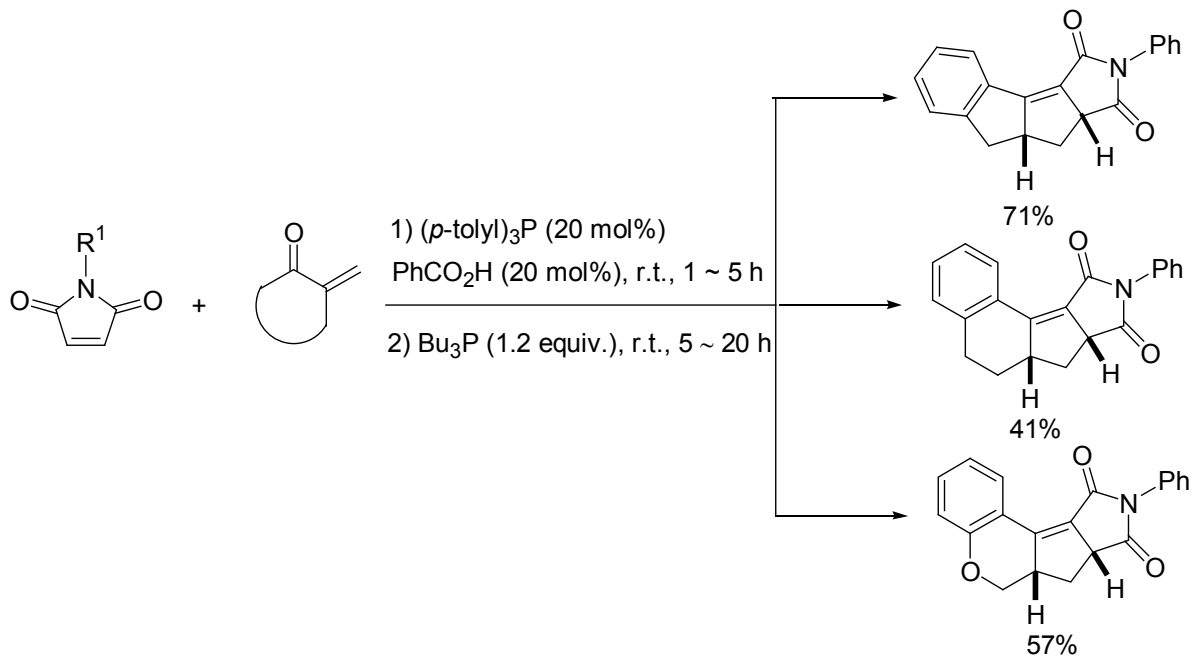

Scheme 35<smiles>[R7][R]([H])C1CC(=O)N([R1])C1=O</smiles>

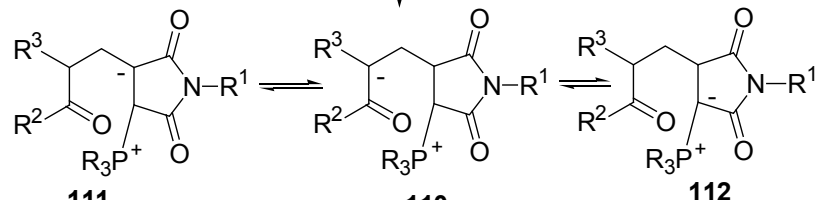
111 110 112 $\nmid \mathrm{PR}_{3}$<smiles>[R]C(=O)C([R])CC1=CC(=O)N([R1])C1=O</smiles>

Scheme 36

生叔膦消除, 生成 $\mathrm{RC}$ 反应产物 106; 当采用离去能力较 差的 $\mathrm{PBu}_{3}$ 时, 110 经氢迁移形成磷叶立德 112, 随后发生 分子内 Wittig 反应, 形成化合物 113, 最后经异构化作 用得到产物 107. 在反应过程中, 稳定的磷叶立德 109 的 形成有利于叔膦对马来酰亚胺进行亲核进攻, 从而实现
与 $\alpha, \beta$-不饱和酥高度化学选择性的 $\mathrm{RC}$ 反应. 条件控制 实验证明, $\mathrm{RC}$ 反应产物 $\mathbf{1 0 6}$ 在 $\mathrm{PBu}_{3}$ 的参与下, 能顺利转 化为双环产物 107 , 而 $\left(p\right.$-toyl) ${ }_{3} \mathrm{P}$ 则不能促进分子内 Wittig 反应的发生, 但在 RC 反应过程中, 离去能力较好 的 $(p \text {-toyl })_{3} \mathrm{P}$ 表现出优越的催化活性, 这些研究结果再次 体现了叔膦对反应的强大调控能力.

最近，黄有等 ${ }^{[49}$ 报道了 $\mathrm{PBu}_{3}$ 促进下共轭二烯烃 114 与活化烯烃 115 的环化反应(Scheme 37). 研究发现, 当 共轭二烯烃一端取代基为酯基时, 主要在叔膦的催化下 生成双环化合物 116; 但当其两端取代基都为酮羰基时, 则在叔膦的参与下生成叶立德产物 117.

\section{2 叔膦促进下缺电子烯烃与亚胺的环化反应}

2009 年, Marinetti 等 ${ }^{[50]}$ 发现，共轭二烯烃 118 可以 在叔膦的催化下，与磺酰亚胺发生环化反应，生成多取 代的二氢吡咯衍生物 119 (Scheme 38). 研究发现, 共轭 二烯烃两端的拉电子基团可以同为酮羰基，或者一端是 酮羰基另一端是酯基，但两端不能同为酯基. 反应机理 如 Scheme 38 所示, 叔膦对反应物 118 亲核进攻产生烯 醇负离子中间体 120 , 随后对亚胺亲核加成得到中间体 121, 121 经分子内 Michael 加成生成中间体 122, 最后经 氢转移及叔膦的消除, 得到反应产物 119. 在此反应 


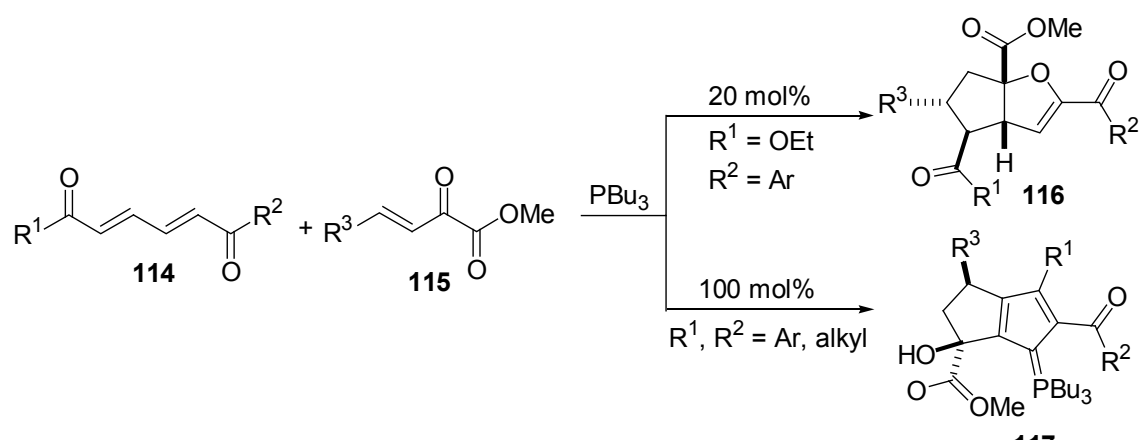

117

Scheme 37

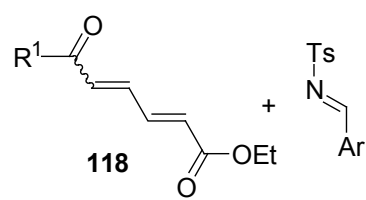

$\mathrm{R}^{1}=$ aryl, alkyl

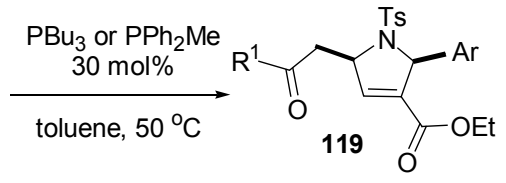

Yield $32 \% \sim 92 \%$ dr 80:20 to > 99:1<smiles>[R17]C(=O)/C=C\C=C\C(=O)OCC</smiles><smiles>[R]C(=O)/C=C\C(=P[PH2+])[C@H](C(=O)OCC)C([Al])[Al]</smiles><smiles>[R]C(=O)CC1C=C(C(=O)OCC)C([Al])[NH+]1[3H]</smiles>



123

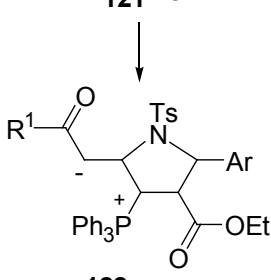

Scheme 38

中, 叔膦区域选择性地进攻与酯基相连的 $\mathrm{C}=\mathrm{C}$ 键, 而 与酮羰基相连的 $\mathrm{C}=\mathrm{C}$ 键则作为环化过程的 Michael 受 体. 作者认为, 两种烯醇负离子对亚胺亲核加成反应速 率的不同，是影响反应区域选择性的可能因素.

最近, 钟国富等 ${ }^{[51]}$ 实现了叔膦催化下 $\alpha, \beta$-不饱和酮 88 与 $\alpha, \beta$-不饱和亚胺 124 的[4+2]环化反应, 高度立体 选择性地合成了四氢吡啶衍生物 125 (Eq. 11). 研究发 现, 该反应要在质子性添加剂对甲氧基苯酚存在的条件 下, 才能取得较高收率及立体选择性. 机理研究表明, 反应先经过了一个叔膦催化的分子间 aza-RauhutCurrier 反应，随后再发生了一个分子内 Michael 加成的 反应过程. 首先, 叔膦对活化烯烃 88 亲核进攻得到烯醇 负离子 126, 随后对 $\alpha, \beta$-不饱和亚胺 124 亲核加成得到中 间体 $127 \mathrm{~A}, 127 \mathrm{~A}$ 转化为 $127 \mathrm{~B}$ 后经氢迁移生成烯醇负离 子 128,128 消除叔膦得到 129 , 随后异构化为 130 , 最后 发生分子内 Michael 加成(IMMA)得到产物 125 (Scheme 39). 酚类质子性添加剂对最后分子内 Michael 加成过程 起到促进作用, 故其存在有利于反应发生. 在此研究的 基础之上，该课题组 ${ }^{[52]}$ 利用天然氨基酸衍生的双功能手
性叔膦催化剂, 顺利地实现了该反应的不对称转化, 并 取得了优秀的对映体选择性，提供了一种高效合成具有 光学活性的四氢吡啶衍生物的便捷途径.

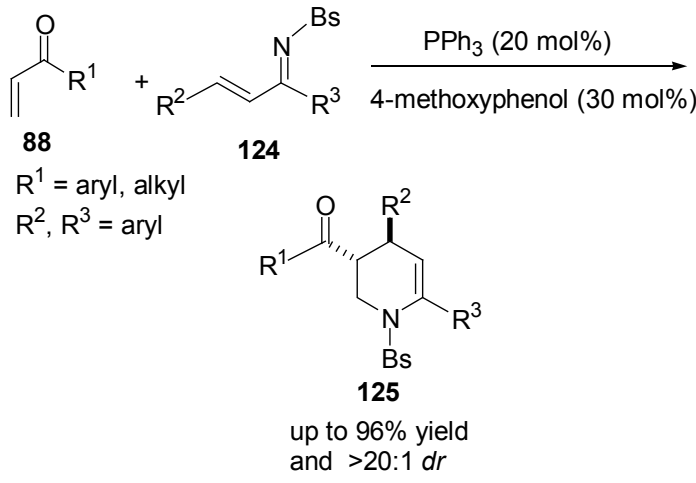

2013 年，施敏等 ${ }^{[53]}$ 采用相似的反应策略，利用天然 氨基酸衍生的多功能手性叔膦催化剂, 实现了 $\alpha, \beta$-不饱 和酩与靛红衍生的 $\alpha, \beta$-不饱和磺酰亚胺的不对称 $[4+2]$ 环化反应，以较高的收率、非对映体选择性与对映体选 择性合成了羟吲哚螺二氢吡啶衍生物(Eq. 12). 


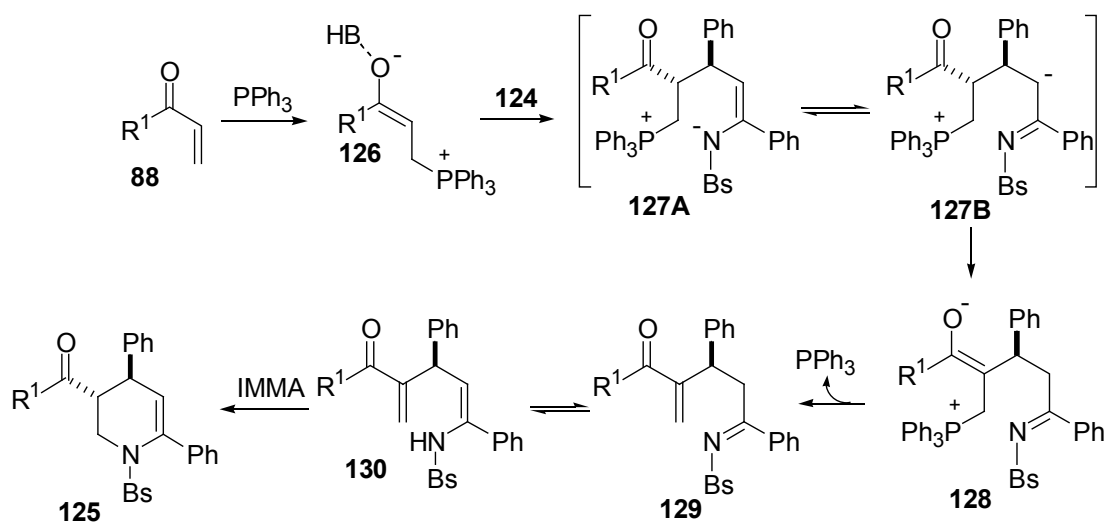

Scheme 39

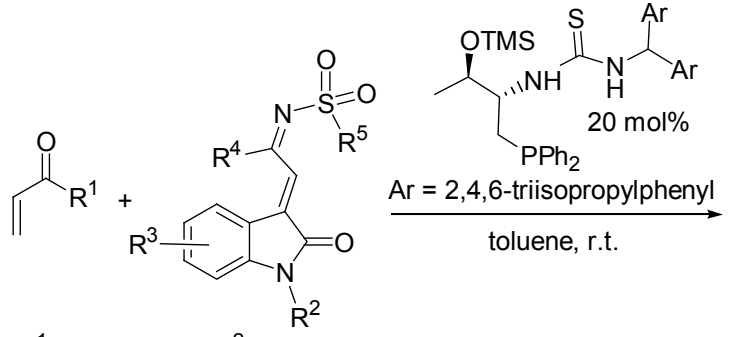

$\mathrm{R}^{1}=\mathrm{Me}, \mathrm{Et}, \mathrm{Ph} ; \mathrm{R}^{2}=\mathrm{Me}, \mathrm{Bn}, 3$,5-dimethlybenzyl

$\mathrm{R}^{3}=\mathrm{H}, \mathrm{F}, \mathrm{Cl}, \mathrm{Br}, \mathrm{OMe} ; \mathrm{R}^{4}=$ aryl, alkyl

$\mathrm{R}^{5}=4$-methylphenyl, naphth-1-yl,

2,4,6-triisopropylphenyl

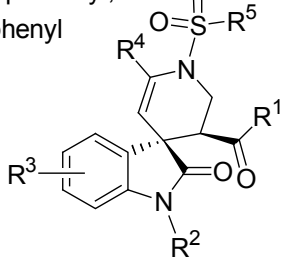

Yield $64 \% \sim 88 \%$

dr 6:1 20:1

ee $87 \%$ $98 \%$

\section{3 叔膦促进下缺电子烯烃与其他亲电试剂的环化反}

应

在叔膦的促进下, 缺电子烯烃不仅能与活化烯烃及 亚胺串联环化, 还可以与其他亲电试剂发生多种环化反 应. 2010 年，林文伟等 ${ }^{[54]}$ 发现，在三丁基膦促进下且在 碱存在的条件下， $\alpha, \beta$-不饱和酮与酰氯能发生串联环化
反应，生成多取代呋喃衍生物(Scheme 40). 该反应具有 较宽的底物适用范围，包括由 1,3-二酮类化合物、苯甲 酰乙酸乙酯及苯甲酰乙腈与芳香醛衍生的 $\alpha, \beta$-不饱和 酮，都表现出优秀的反应性，能与不同结构的芳香及脂 肪酰氯反应，高收率地生成呋喃衍生物. 机理上，反应 经过了一个 $O$-酰基化-分子内 Wittig 烯化的串联反应过 程. 首先, 叔膦对 $\alpha, \beta$-不饱和酮 131 亲核进攻, 得到烯醇 负离子中间体 133 , 随后与酰氯反应得到 $O$-酰基化中间 体 134, 接着在碱的作用下脱去质子生成磷叶立德 $\mathbf{1 3 5}$, 最后发生分子内 Wittig 烯化反应, 得到呋喃产物 132 (Scheme 40). 在机理研究中, 作者成功分离到烯醇负离 子中间体 133, 并通过控制实验发现，该中间体在碱的 作用下可以进一步与酰氯反应，得到最终呋喃产物，从 而证明了该机理的正确性. 在此研究的基础之上，林文 伟等 ${ }^{[55}$ 从醛、1,3-二羰基化合物及三丁基膦出发，合成 了一系列烯醇负离子, 并成功地将其应用于呋喃衍生物 的构建. 上述反应条件温和，原料简单易得，为高效合 成呋喃衍生物提供了一种便捷途径，在有机合成中具有 较高的应用价值.

随后，该课题组 ${ }^{[56]}$ 进一步将反应中的 $\alpha, \beta$-不饱和酮 底物拓展至查尔酮等. 最近, 该课题组 ${ }^{[57]}$ 直接从水杨醛 衍生物出发, 在叔膦的促进下与酰氯经过相同的转化,

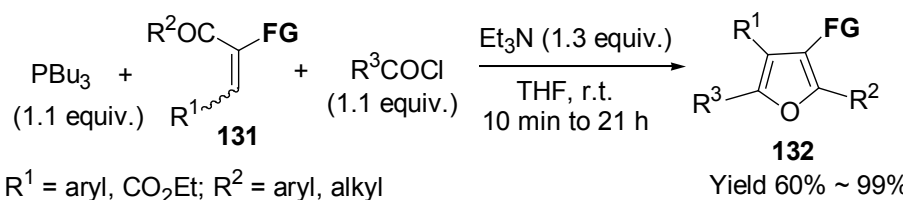

$\mathrm{R}^{3}=$ aryl, alkyl, vinyl

$\mathbf{F G}=\mathrm{COR}_{2}, \mathrm{CO}_{2} \mathrm{Et}, \mathrm{CN}$

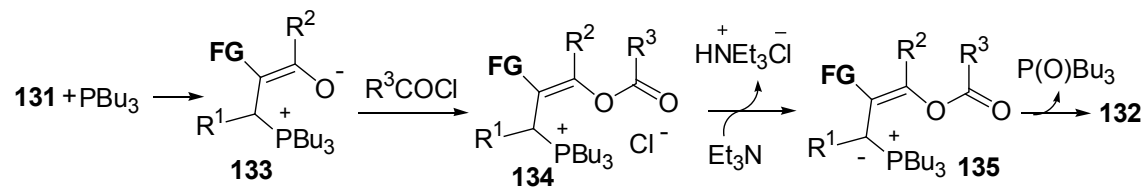

Scheme 40 
合成了双环呋喃、噻吩及吲哚衍生物. 本课题组 ${ }^{[58]}$ 利用 相似的策略, 在三丁基膦的促进下, 从丙烯酸酯等结构 简单的缺电子烯烃出发, 与酰氯经过 $C$-酰基化, $O$-酰基 化, $C$-酰基化及分子内 Wittig 烯化的四重串联, 同样高 效地合成了多取代的呋喃衍生物.

叔膦促进下缺电子烯烃与亲电试剂的环化反应往 往能从简单易得的原料出发, 经过连续的化学转化, 高 效构建复杂的分子骨架, 符合绿色化学特征, 同时具有 较高的原子经济性, 近年来已得到化学家们的广泛关 注, 相信会涌现出更多具有重要用途的合成新方法.

\section{4 总结与展望}

综上所述, 叔膦促进下两种亲电试剂之间的环化反 应, 已成为高效构建不同碳环及杂环化合物的重要方 法. 由于这类反应大都具有原料简单易得、反应条件温 和、无金属试剂参与、立体选择性好等优点, 近十几年 来, 该课题已成为一个研究热点, 涌现了大量高效的合 成新反应. 在此领域中, 缺电子联烯、 $\mathrm{MBH}$ 烯丙基化合 物及缺电子烯烃成为人们广泛研究的对象, 在叔膦的促 进下, 上述化合物表现出丰富的化学反应性, 可以与不 同亲电试剂实现多种类型的环化反应. 从机理上而言, 叔膦促进下两种亲电试剂之间环化反应，一般起始于膦 对活性较高的亲电试剂(如缺电子联烯、 $\mathrm{MBH}$ 烯丙基化 合物、缺电子烯烃等)进行亲核加成，产生两性离子活性 中间体, 随后再与另一种亲电试剂串联环化, 从而实现 环状化合物的合成. 因此, 一方面设计合成新的活性较 高的亲电试剂, 能在叔膦促进下, 产生结构新颖的两性 离子中间体, 从而实现与已有亲电试剂(如活化烯烃、 醛、酮、亚胺等)新的环化反应; 另一方面寻找新的亲电 试剂, 实现与已有两性离子中间体(由叔膦与缺电子联 烯、 $\mathrm{MBH}$ 烯丙基化合物、缺电子烯烃等产生)新的环化 反应，势必能更好地丰富叔膦促进下两种亲电试剂之间 的环化反应类型，同时进一步促进环状化合物合成方法 学的发展.

\section{References}

[1] Quin, L.D. A Guide to Organophosphorus Chemistry, Wiley, New York, 2000.

[2] (a) Wittig, G.; Schöllkopf, U. Chem. Ber. 1954, 87, 1318.

(b) Mitsunobu, O. Synthesis 1981, 1.

(c) Staudinger, H.; Meyer, J. Helv. Chim. Acta 1919, 2, 635.

(d) Xu, S.; He, Z. Chin. J. Org. Chem. 2012, 32, 1159 (in Chinese). (徐四龙, 贺峥杰, 有机化学, 2012, 32, 1159.)

[3] (a) Lu, X.; Zhang, C.; Xu, Z. Acc. Chem. Res. 2001, 34, 535. (b) Methot, J. L.; Roush, W. R. Adv. Synth. Catal. 2004, 348, 1035. (c) Tang, Q.; Tu, A.; Deng, Z.; Hu, M.; Zhong, W. Chin. J. Org. Chem. 2013, 33, 954 (in Chinese).

(唐谦, 涂爱平, 邓真真, 胡梦莹, 钟为慧, 有机化学, 2013, 33, 954.) (d) Ye, L.-W.; Zhou, J.; Tang, Y. Chem. Soc. Rev. 2008, 37, 1140. (e) Cowen, B. J.; Miller, S. J. Chem. Soc. Rev. 2009, 38, 3102.

(f) Zhao, Q.-Y.; Lian, Z.; Wei, Y.; Shi, M. Chem. Commun. 2012, 48, 1724.

(g) Fan, Y. C.; Kwon, O. Chem. Commun. 2013, 49, 11588.

(h) Wang, Z.; Xu, X.; Kwon, O. Chem. Soc. Rev. 2014, 43, 2927.

[4] Zhang, C.; Lu, X. J. Org. Chem. 1995, 60, 2906.

[5] (a) Xia, Y.; Liang, Y.; Chen, Y.; Wang, M.; Jiao, L.; Huang, F.; Liu, S.; Li, Y.; Yu, Z.-X. J. Am. Chem. Soc. 2007, 129, 3470.

(b) Liang, Y.; Liu, S.; Xia, Y.; Li, Y.; Yu, Z.-X. Chem.-Eur. J. 2008, 14, 4361.

[6] (a) Mercier, E.; Fonovic, B.; Henry, C.; Kwon, O.; Dudding, T. Tetrahedron Lett. 2007, 48, 3617.

(b) Dudding, T.; Kwon, O.; Mercier, E. Org. Lett. 2006, 8, 3643.

[7] (a) Xu, Z.; Lu, X. J. Org. Chem. 1998, 63, 5031.

(b) Xu, Z.; Lu, X. Tetrahedron Lett. 1999, 40, 549.

(c) Xu, Z.; Lu, X. Tetrahedron Lett. 1997, 38, 3461.

[8] Zhu, X.-F.; Henry, C. E.; Kwon, O. Tetrahedron 2005, 61, 6276.

[9] Zhang, B.; He, Z.; Xu, S.; Wu, G.; He, Z. Tetrahedron 2008, 64, 9471.

[10] (a) Hartley, R. C.; Caldwell, S. T. J. Chem. Soc., Perkin Trans. 1 2000, 477.

(b) Yong, S. R.; Williams, M. C.; Pyne, S. G.; Ung, A. T.; Skelton, B. W.; White, A. H.; Turner, P. Tetrahedron 2005, 61, 8120.

[11] (a) Pham, T. Q.; Pyne, S. G.; Skelton, B. W.; White, A. H. J. Org. Chem. 2005, 70, 6369.

(b) Wu, H.; Zhang, H.; Zhao, G. Tetrahedron 2007, 63, 6454.

(c) Du, Y.; Lu, X. J. Org. Chem. 2003, 68, 6463.

(d) Wang, J.-C.; Krische, M. J. Angew. Chem., Int. Ed. 2003, 42, 5855 .

(e) Andrews, I. P.; Kwon, O. Chem. Sci. 2012, 3, 2510.

[12] Xu, S.; Zhou, L.; Ma, R.; Song, H.; He, Z. Chem. Eur. J. 2009, 15, 8698.

[13] Wang, T.; Ye, S. Org. Biomol. Chem. 2011, 9, 5260.

[14] Zhu, X.-F.; Lan, J.; Kwon, O. J. Am. Chem. Soc. 2003, 125, 4716.

[15] (a) Tran, Y. S.; Kwon, O. J. Am. Chem. Soc. 2007, 129, 12632.

(b) Tran, Y. S.; Martin, T. J.; Kwon, O. Chem. Asian J. 2011, 6, 2101.

[16] (a) Villa, R. A.; Xu, Q.; Kwon, O. Org. Lett. 2012, 14, 4634.

(b) Tran, Y. S.; Kwon, O. Org. Lett. 2005, 7, 4289.

[17] (a) Wurz, R. P.; Fu, G. C. J. Am. Chem. Soc. 2005, 127, 12234.

(b) Zhong, F.; Han, X.; Wang, Y.; Lu, Y. Chem. Sci. 2012, 3, 1231.

(c) Xiao, H.; Chai, Z.; Cao, D.; Wang, H.; Chen, J.; Zhao, G. Org. Biomol. Chem. 2012, 10, 3195.

[18] Wang, T.; Ye, S. Org. Lett. 2010, 12, 4168.

[19] Li, E.; Huang, Y.; Liang, L.; Xie, P. Org. Lett. 2013, 15, 3138.

[20] Gicquel, M.; Gomez, C.; Retailleau, P.; Voituriez, A.; Marinetti, A. Org. Lett. 2013, 15, 4002.

[21] (a) Meng, X. T.; Huang, Y.; Chen, R. Y. Org. Lett. 2009, 11, 137. (b) Sun, Y.-W.; Guan, X.-Y.; Shi, M. Org. Lett. 2010, 12, 5664. (c) Kumar, K.; Kapoor, R.; Kapur, A.; Ishar, M. P. S. Org. Lett. 2000, 2, 2023.

(d) Kumar, K.; Kapur, A.; Ishar, M. P. S. Org. Lett. 2000, 2, 787. (e) Liu, B.; Davis, R.; Joshi, B.; Reynolds, D. W. J. Org. Chem. 2002, 67, 4595 .

(f) Zhu, X. F.; Henry, C. E.; Wang, J.; Dudding, T.; Kwon, O. Org. Lett. 2005, 7, 1387.

(g) Zhu, X.-F.; Schaffner, A.-P.; Li, R. C.; Kwon, O. Org. Lett. 2005, 7, 2977.

(h) Creech, G. S.; Kwon, O. Org. Lett. 2008, 10, 429.

(i) Jing, C,; Na, R.; Wang, B.; Liu, H.; Zhang, L.; Liu, J.; Wang, M.; Zhong, J.; Kwon, O.; Guo, H. Adv. Synth. Catal. 2012, 354, 
1023.

(j) Zheng, J.; Huang, Y.; Li, Z. Org. Lett. 2013, 15, 5064.

(k) Li, E.; Jia, P.; Liang, L.; Huang, Y. ACS Catal. 2014, 4, 600.

(1) Li, E.; Huang, Y. Chem. Commun. 2014, 50, 948.

(m) Li, E.; Huang, Y. Chem. Eur. J. 2014, 20, 3520.

[22] Guo, H.; Xu, Q.; Kwon, O. J. Am. Chem. Soc. 2009, 131, 6318.

[23] Na, R.; Jing, C.; Xu, Q.; Jiang, H.; Wu, X.; Shi, J.; Zhong, J.; Wang, M.; Benitez, D.; Tkatchouk, E.; Goddard, W. A.; Guo, H.; Kwon, O. J. Am. Chem. Soc. 2011, 133, 13337.

[24] Du, Y.; Lu, X.; Zhang, C. Angew. Chem., Int. Ed. 2003, 42, 1035.

[25] Feng, J.; Lu, X.; Kong, A.; Han, X. Tetrahedron 2007, 63, 6035.

[26] Zheng, S.; Lu, X. Tetrahedron Lett. 2009, 50, 4532.

[27] Deng, H.-P.; Wei, Y.; Shi, M. Org. Lett. 2011, 13, 3348.

[28] Zhong, F.; Han, X.; Wang, Y.; Lu, Y. Angew. Chem., Int. Ed. 2011, $50,7837$.

[29] Tan, B.; Candeias, N. R.; Barbas, C. F. J. Am. Chem. Soc. 2011, $133,4672$.

[30] Zhong, F.; Chen, G.-Y.; Han, X.; Yao, W.; Lu, Y. Org. Lett. 2012, $14,3764$.

[31] Zheng, S.; Lu, X. Org. Lett. 2008, 10, 4481.

[32] Du, Y.; Feng, J.; Lu, X. Org. Lett. 2005, 7, 1987.

[33] Zheng, S.; Lu, X. Org. Lett. 2009, 11, 3978.

[34] Zhou, R.; Wang, J.; Song, H.; He, Z. Org. Lett. 2011, 13, 580.

[35] Chen, Z.; Zhang, J. Chem. Asian J. 2010, 5, 1542.

[36] Tian, J.; Zhou, R.; Sun, H.; Song, H.; He, Z. J. Org. Chem. 2011, 76, 2374.

[37] Zhou, R.; Duan, C.; Yang, C.; He, Z. Chem. Asian. J. 2014, 9, 1183.

[38] Xie, P.; Huang, Y.; Chen, R. Org. Lett. 2010, 12, 3768.

[39] (a) Zhang, X.; Deng, H.-P.; Huang, L.; Wei, Y.; Shi, M. Chem. Commun. 2012, 48, 8664.

(b) Hu, F.-L.; Wei, Y.; Shi, M. Chem. Commun. 2014, 50, 8912.

[40] Xie, P.; Huang, Y.; Chen, R. Chem. Eur. J. 2012, 18, 7362.

[41] Xie, P.; Li, E.; Zheng, J.; Li, X.; Huang, Y.; Chen, R. Adv. Synth. Catal. 2013, 355, 161.

[42] Zheng, J.; Huang, Y.; Li, Z. Chem. Commun. 2014, 50, 5710.

[43] Aroyan, C. E.; Dermenci, A.; Miller, S. J. Tetrahedron 2009, 65,
4069.

[44] (a) Basavaiah, D.; Rao, A. J.; Satyanarayana, T. Chem. Rev. 2003, 103, 811 .

(b) Basavaiah, D.; Reddy, B. S.; Badsara, S. S. Chem. Rev. 2010, 110, 5447.

(c) Cui, P.-L.; Wang, C.; Guo, X.-M.; Liu, H.-Y.; Feng, T. Chin. J. Org. Chem. 2008, 28, 194 (in Chinese).

(崔朋雷, 王春, 果秀敏, 刘海燕, 冯涛, 有机化学, 2008, 28, 194.)

[45] Cai, L.; Zhang, B.; Wu, G.; Song, H.; He, Z. Chem. Commun. 2011, $47,1045$.

[46] Zhou, R.; Wang, J.; Tian, J.; He, Z. Org. Biomol. Chem. 2012, 10, 773.

[47] Hu, F.-L.; Wei, Y.; Shi, M. Adv. Synth. Catal. 2014, 356, 736.

[48] Zhou, R.; Wang, J.; Yu, J.; He, Z. J. Org. Chem. 2013, 78, 10596.

[49] Ma, J.; Xie, P.; Hu, C.; Huang, Y.; Chen, R. Chem. Eur. J. 2011, $17,7418$.

[50] Schuler, M.; Duvvuru, D.; Retailleau, P.; Betzer, J.-F.; Marinetti, A. Org. Lett. 2009, 11, 4406.

[51] Shi, Z.; Tong, Q.; Leong, W. W. Y.; Zhong, G. Chem. Eur. J. 2012, $18,9802$.

[52] Shi, Z.; Yu, P.; Loh, T.-P.; Zhong, G. Angew. Chem., Int. Ed. 2012, 51,7825 .

[53] (a) Zhang, X.-N.; Chen, G.-Q.; Dong, X.; Wei, Y.; Shi, M. $A d v$. Synth. Catal. 2013, 355, 3351.

(b) Zhang, X.-N.; Dong, X.; Wei, Y.; Shi, M. Tetrahedron 2014, $70,2838$.

[54] Kao, T.-T.; Syu, S.; Jhang, Y.-W.; Lin, W. Org. Lett. 2010, 12, 3066.

[55] Lee, C.-J.; Jang, Y.-J.; Wu, Z.-Z.; Lin, W. Org. Lett. 2012, 14, 1906.

[56] Chen. K.-W.; Syu, S.; Jang, Y.-J.; Lin, W. Org. Biomol. Chem. 2011, 9, 2098.

[57] Syu. S.; Lee, Y.-T.; Jang, Y.-J.; Lin, W. Org. Lett. 2011, 13, 2970.

[58] Wang, J.; Zhou, R.; He, Z.-R.; He, Z. Eur. J. Org. Chem. 2012, 6033. 